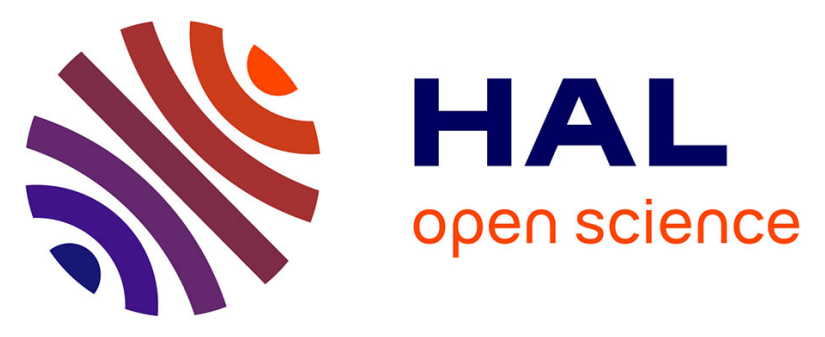

\title{
Hyperspectral Earth Observation from IASI: four years of accomplishments
}

Fiona Hilton, Raymond Armante, Thomas August, Chris Barnet, Aurelie Bouchard, Claude Camy-Peyret, Virginie Capelle, Lieven Clarisse, Cathy Clerbaux, Pierre-François Coheur, et al.

\section{To cite this version:}

Fiona Hilton, Raymond Armante, Thomas August, Chris Barnet, Aurelie Bouchard, et al.. Hyperspectral Earth Observation from IASI: four years of accomplishments. Bulletin of the American Meteorological Society, 2012, 93 (3), pp.347-370. 10.1175/BAMS-D-11-00027.1 . hal-00625913

\section{HAL Id: hal-00625913 https://hal.science/hal-00625913}

Submitted on 19 Dec 2020

HAL is a multi-disciplinary open access archive for the deposit and dissemination of scientific research documents, whether they are published or not. The documents may come from teaching and research institutions in France or abroad, or from public or private research centers.
L'archive ouverte pluridisciplinaire HAL, est destinée au dépôt et à la diffusion de documents scientifiques de niveau recherche, publiés ou non, émanant des établissements d'enseignement et de recherche français ou étrangers, des laboratoires publics ou privés. 


\title{
HYPERSPECTRAL EARTH OBSERVATION FROM IASI Five Years of Accomplishments
}

by Fiona Hilton, Raymond Armante, Thomas August, Chris Barnet, Aurelie Bouchard, Claude Camy-Peyret, Virginie Capelle, lieven Clarisse, Cathy Clerbaux, Pierre-Francois Coheur, Andrew Collard, Cyril Crevoisier, Gaelle Dufour, David Edwards, Francois Faijan, Nadia Fourrié, Antonia Gambacorta, Mitchell Goldberg, Vincent Guidard, Daniel Hurtmans, Samuel Illingworth, Nicole Jacquinet-Husson, Tobias Kerzenmacher, Dieter Klaes, lydie Lavanant, Guido Masiello, Marco Matricardi, Anthony McNally, Stuart Newman, Edward Pavelin, Sebastien Payan, Eric Péquignot, Sophie Peyridieu, Thierry Phulpin, John Remedios, Peter Schlüssel, Carmine Serio, larrabee Strow, Claudia Stubenrauch, Jonathan Taylor, David Tobin, Walter Wolf, and Daniel Zhou

\begin{abstract}
IASI has delivered significant advances in remote sensing capabilities for numerical weather prediction and atmospheric composition monitoring, and promises to provide an excellent dataset for climate studies.
\end{abstract}

T

HE IASI INSTRUMENT. The first Infrared Atmospheric Sounding Interferometer (IASI) was launched in October 2006 on the European Organisation for the Exploitation of Meteorological Satellites's (EUMETSAT's) Meteorological Operation $($ MetOP)-A satellite. The instrument and its successors will continue to operate until 2020 on the current MetOp platform and two follow-on satellites. IASI is a Michelson interferometer covering the infrared spectral domain from 645 to $2,760 \mathrm{~cm}^{-1}(3.62-15.5 \mu \mathrm{m})$. The mission is dedicated to highresolution atmospheric sounding, with a mission accuracy requirement of $1 \mathrm{~K}$ for tropospheric temperature and $10 \%$ for humidity for a vertical resolution of $1 \mathrm{~km}$, and the retrieval of trace gas total column amounts (such as $\mathrm{CO}_{2}, \mathrm{O}_{3}, \mathrm{~N}_{2} \mathrm{O}, \mathrm{CO}$, and $\left.\mathrm{CH}_{4}\right)$. The innovative instrument, which is described in Cayla (2001) and Chalon et al. (2001), is shown in Fig. 1. IASI was designed by the Centre National d'Etudes Spatiales (CNES), jointly financed by CNES and EUMETSAT, and built by Thales Alenia Space.

Smith et al. (2009) describe the evolution of infrared spaceborne instruments and the benefits to atmospheric sounding from achieving measurements

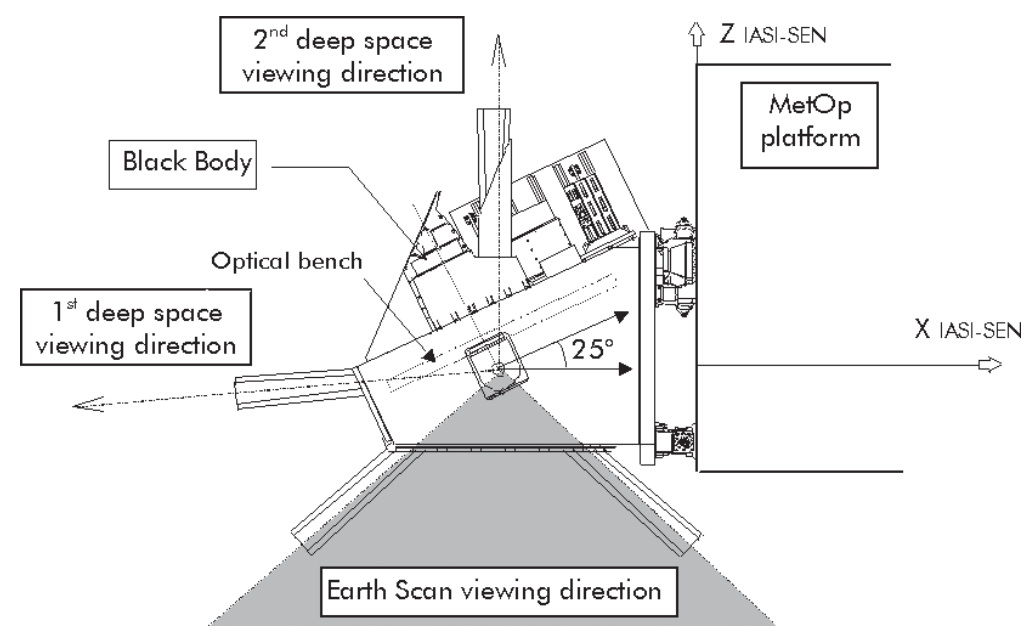

FIG. I. Diagram of the IASI instrument. 
at progressively higher spectral resolution. IASI is the first purpose-built operational hyperspectral instrument. (By hyperspectral we refer to the ability to measure over hundreds or thousands of spectral bands.) The exploitation of hyperspectral data was greatly advanced following the launch of the pioneering Atmospheric Infrared Sounder (AIRS) in 2002 (see Chahine et al. 2006), which, in contrast to IASI, is a grating spectrometer.

The MetOp satellite series is Europe's contribution to the Initial Joint Polar-Orbiting Operational Satellite System (IJPS) - a series of low-Earth-orbiting satellites in sun-synchronous orbit. MetOp provides coverage in the morning orbit, with a local equator crossing time of 0930 local time (LT) for the descending node. The afternoon orbit is served by

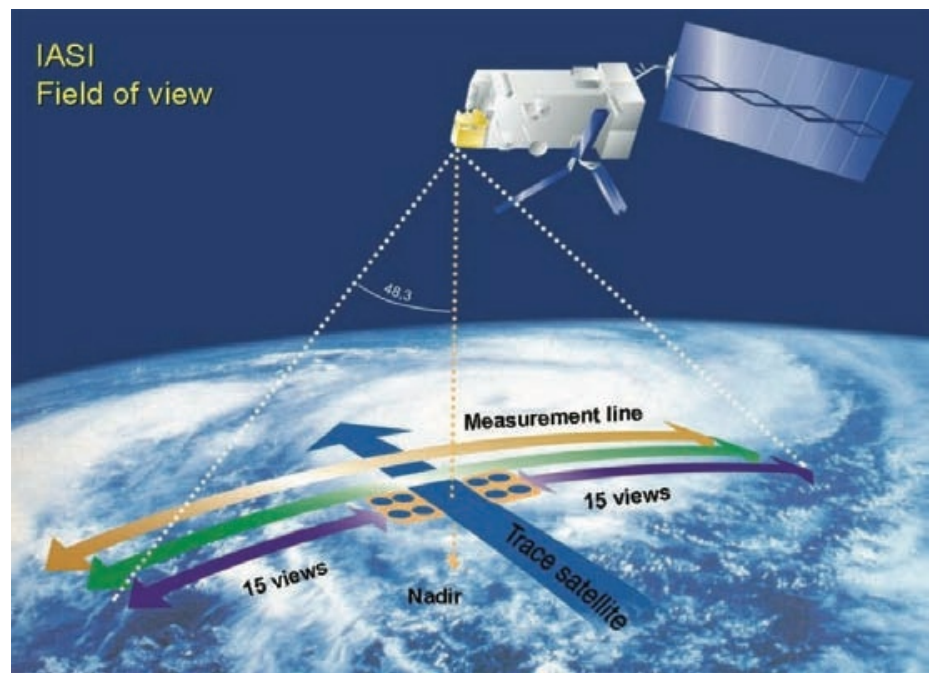

FIG. 2. IASI scan geometry.
U.S. satellites operated by the National Oceanic and Atmospheric Administration (NOAA), with the current satellite being NOAA-19. IASI is one of eight meteorological instruments on board MetOp; more details and an overview on the products provided can be found in Klaes et al. (2007).

IASI is a cross-track scanner, with a total of 30 ground fields of regard (FOR) per scan. Each FOR measures a $2 \times 2$ array of footprints, each of which has a $12-\mathrm{km}$ diameter at nadir (Fig. 2). The spectrum is measured in three wavelength bands (8.26-15.5, 5.0-8.26, and 3.62-5.0 $\mu \mathrm{m}$; see Siméoni et al. 2004), each of which has a separate detector, allowing the continuous spectral coverage with no gaps. In wavenumber (reciprocal wavelength) units the band ranges are $645-1,210,1,210-2,000$, and $2,000-2,760 \mathrm{~cm}^{-1}$, respectively. The raw measurements made by the instrument are interferograms that are processed to radiometrically calibrated spectra on board the satellite using two calibration views, which can be identified on Fig. 1: the first cold space (CS1) view and internal blackbody (BB) view. Further processing by the terrestrial data reception center delivers apodized radiances (known as the level 1c product) to the end user. The radiances consist of 8,461 spectral samples (commonly referred to as "channels") every $0.25 \mathrm{~cm}^{-1}$, with an instrument response function of $0.5 \mathrm{~cm}^{-1}$ half-width after apodization. Provided with the radiances, information is derived from coregistered pixels of the Advanced Very High Resolution Radiometer (AVHRR) affiliations: Hilton, Newman, Pavelin, and Taylor-Met Office, Exeter, United Kingdom; Armante, Capelle, Crevolsier, JacquinetHusson, Peyridieu, and Stubenrauch — Laboratoire de Météorologie Dynamique/CNRS/IPSL, Paris, France; August, KLAES, AND SCHLÜsSel一 EUMETSAT, Darmstadt, Germany; BARNET, GoldBERG, AND WolfNOAA/NESDIS, Camp Springs, Maryland; BOUCHARD, FourRIÉ, GuIDARD-Météo-France, and CNRS/CNRM-GAME, Paris, France; Camy-Peyret and Payan-UMPC University Paris 06, Paris, France; Clarisse, Coheur, and Hurtmans-Spectroscopie de l'Atmosphère, Chimie Quantique et Photophysique, Université Libre de Bruxelles, Brussels, Belgium; ClerbauX-UPMC University Paris 06, Paris, and Université Versailles St.-Quentin, Versailles, and CNRS/INSU, LATMOS-IPSL, Paris, France; ColLARD—NOAA/NCEP/EMC/IMSG, Camp Springs, Maryland; Dufour-LISA-CNRS/Université de Paris 12 et Paris 7, Paris, France; EdWARDS—National Center for Atmospheric Research, Boulder, Colorado; Faljan And Lavanant-Centre de Météorologie Spatiale, Météo-France, Lannion, France; GAMBACORTADell, Inc., Round Rock, Texas; IlLINGWORTH AND RemedIOS-University of Leicester, Leicester, United Kingdom; KeRZENMACHER—Belgian Institute for Space Aeronomy, Brussels, Belgium; MAsIeLlo AND SerIODIFA, Università degli Studi della Basilicata, Potenza, Italy; MATRICARDI AND MCNALLY -European Centre for Medium-Range Weather Forecasts, Reading, United Kingdom; PÉQUIGNOT AND PHULPIN—CNES, Toulouse, France; STROW-University of Maryland, Baltimore County, Baltimore, Maryland; ToBIN-Space Science and Engineering Center, University of Wisconsin-Madison, Madison, Wisconsin; ZHOUNASA Langley Research Center, Hampton, Virginia CORRESPONDING AUTHOR: Fiona Hilton, Met Office, Fitzroy Road, Exeter, EXI 3PB United Kingdom

E-mail: fiona.hilton@metoffice.gov.uk

The abstract for this article can be found in this issue, following the table of contents.

DOI:10.1175/BAMS-D-II-00027.|

In final form 10 August 2011

(C)2012 American Meteorological Society 
imager, which helps to characterize the heterogeneity of the scene (including cloud fraction) within each IASI pixel.

The stability of the instrument is monitored routinely by the CNES Technical Expertise Centre, using onboard measurements, and by EUMETSAT, where stable, clear fields of view are compared with simulated radiances from numerical weather prediction model output. Since its launch, the instrument performance, which is discussed further in the next section, has been extremely stable. The instrument is already being used as a tool to investigate the spectral response function of other radiometers in detail (see "IASI performance and calibration"). Data availability has been excellent at around $96 \%$, and measures have been put in place to limit the duration of any interruptions.

IASI level 1c data and level 2-derived products (Schlüssel et al. 2005) are delivered in near-real time by the EUMETCast distribution system. They are also available online from the EUMETSAT Data Centre (www.eumetsat.int/Home/Main/DataAccess /EUMETSATDataCentre/index.htm) within $7 \mathrm{~h}$ of acquisition. For organizations not covered by the EUMETCast system, a selection of 300 channels is distributed via the Global Telecommunications System (GTS) of the World Meteorological Organization (WMO). The full suite of operational products available from EUMETSAT is summarized in Table 1. Also available from September 2010, currently as an experimental product, are level 1c spectra compressed into principal component (PC) scores (see "Impact of IASI in NWP"). NOAA/National Environmental Satellite, Data, and Information Service (NESDIS)/Center for Satellite Applications and Research (STAR; www.class.ncdc.noaa.gov /saa/products/welcome) ${ }^{1}$ also distributes a channel subset of the IASI spectrum in near-real time along with PC scores [using a method developed for AIRS as described in Goldberg et al. (2003)], cloud-cleared radiances, temperature, water vapor, and trace gas products.

\footnotetext{
${ }^{1}$ The NESDIS is part of NOAA. STAR is the science arm of NESDIS responsible for processing the IASI data in nearreal time, while NOAA/CLASS at the National Climatic Data Center (NCDC) is responsible for distribution.
}

IASI PERFORMANCE AND CALIBRATION. Before data from a new sensor can be used with confidence, the noise characteristics of the instrument must be well defined. It is crucial for climate monitoring, and highly desirable for NWP, that any biases (absolute errors relative to the truth) that might affect satellite radiances are both understood and characterized. Such biases may arise from uncertainties in the calibration of the sensor (e.g., solar intrusion or blackbody nonlinearity), or from a lack of knowledge of, or changes in, the spectral response of channels. Biases may vary with time (e.g., resulting from an increase in instrument temperature) and scan position, and on orbital and seasonal time scales. Significant effort has been made to ensure the quality of IASI data.

Routine instrument performance monitoring. Routine monitoring of IASI data and calibration and validation activities by CNES and EUMETSAT ensure full characterization of the instrument and verify that the performance meets the requirements. Figure 3 shows IASI noise along with the instrument specification, and indicates that the noise is stable and within specification, except below $680 \mathrm{~cm}^{-1}$, above $2,300 \mathrm{~cm}^{-1}$, and in small overlap regions where information from two detector bands are merged. Small signs of contamination resulting from the buildup of ice on the instrument lens can be deduced from the small increase in noise over time between 700 and $1,000 \mathrm{~cm}^{-1}$. The buildup is managed by occasional decontamination procedures before the effect on the spectra becomes

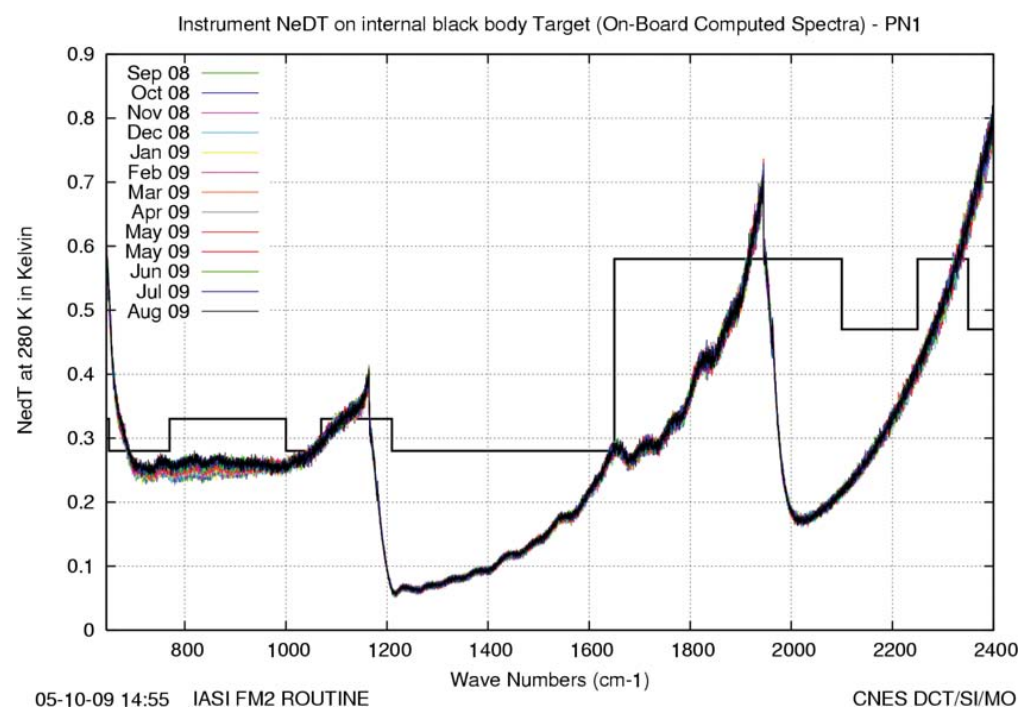

FIG. 3. Measured IASI noise [noise-equivalent brightness temperature (NE $\Delta T)$ ] expressed at a reference point of $280 \mathrm{~K}$, spanning the spectral range $645-2,400 \mathrm{~cm}^{-1}(15.5-4.17 \mu \mathrm{m})$. The stability of the noise performance over I yr is shown (see legend). The IASI noise design specification is shown (stepped black line). 


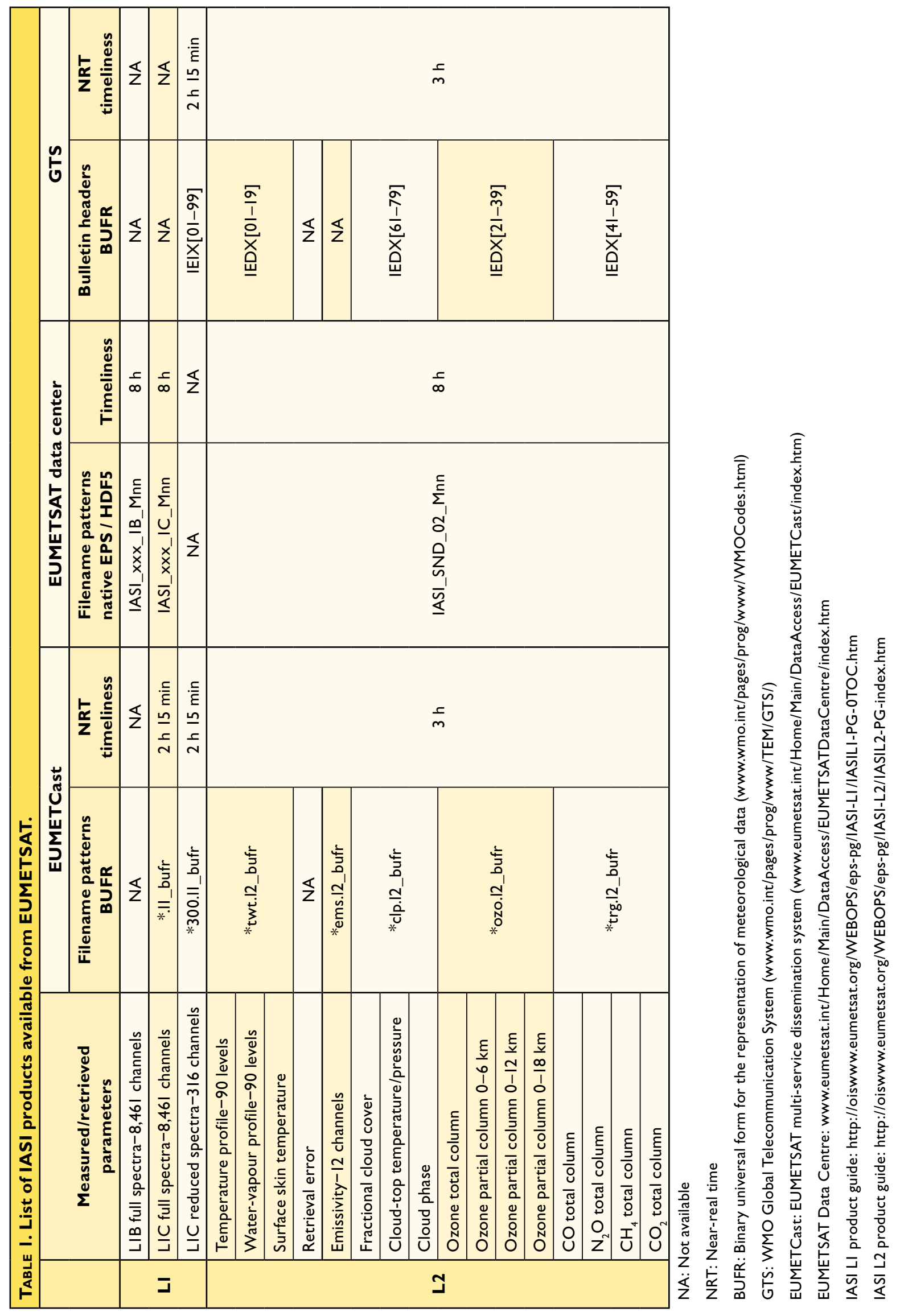


too great. Blumstein et al. (2007) describe routine inflight calibration and validation activities, which can be split into three more or less independent classes: spectral, radiometric, and geometric.

Validation of the spectral calibration is performed using a line-by-line radiative transfer model together with ground truth measurements or NWP data for Earth scenes with very good spatial uniformity, such as clear-sky conditions over the sea. The spectral calibration accuracy is within the specification of

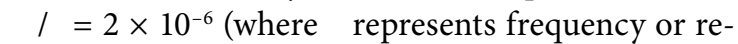
ciprocal wavelength).

Radiometric calibration of the IASI level 1 products is based on the cold and hot calibration views (see Fig. 1), which are each measured every $8 \mathrm{~s}$. Prelaunch testing of the instrument was carried out using blackbodies at well-known temperature, and the stability of the instrument is monitored in flight. In-depth evaluation is routinely performed by comparing IASI with other instruments, such as AVHRR and the High Resolution Infrared Radiation Sounder (HIRS) on the MetOp platform. These instruments have a much lower spectral resolution than that of IASI, but their measurements can be compared by integrating the IASI radiance spectrum over the response function of the low-resolution instrument. Such intercomparisons suggest that the absolute calibration of the sounder is better than $0.35 \mathrm{~K}$, and therefore fully within the specification of $0.5 \mathrm{~K}$.

The geolocation of IASI products is based on coregistration with AVHRR. In addition to the interferometer, IASI has an integrated infrared imager, the Integrated Imaging Subsystem (IIS), with $64 \times$ 64 pixels to each IASI footprint. Every IIS image is coregistered with AVHRR so that the ground position of the image, and thus the associated sounder footprint, can be determined. Validation of the geometric calibration is carried out frequently, using scenes with high-contrast features (e.g., coastlines), giving the geolocation error of IASI to be within $100 \mathrm{~m}$ with respect to AVHRR.

Independent radiance calibration and validation studies. Various independent intercalibration studies between IASI and other instruments are ongoing within the Global Satellite Inter-Calibration System (GSICS; see www.wmo.int/pages/prog/sat/GSICS/index en.html; e.g., Hewison and König 2008; Goldberg et al. 2011). GSICS aims to ensure the comparability of satellite measurements performed from different instruments (sounders/imagers, infrared/microwave) and platforms, to interpret the differences, and to link the measurements to absolute references and standards. Intercomparisons have been performed with HIRS, AIRS, the Spinning Enhanced Visible and Infrared Imager (SEVIRI), and the Advanced Along-Track Scanning Radiometer (AATSR) using simultaneous nadir overpass (SNO) methods or double-difference (DD) methods (e.g., Cao et al. 2009; Illingworth et al. 2009; Hewison 2008a,b; Tobin 2008; Wang and Cao 2008). Biases are also characterized via the study of residuals between IASI observations and simulations based on radiative transfer code and collocated radiosoundings (Blumstein et al. 2010). These intercalibration studies have confirmed the remarkable accuracy and stability of IASI as measured by CNES and EUMETSAT.

Illingworth et al. (2009) used SNOs to compare the in-flight radiometric performance of IASI in the 11- and $12-\mu \mathrm{m}$ regions with that of AATSR on the Environmental Satellite (Envisat) platform and identified a suspected spectral filter uncertainty of around $0.2 \mathrm{~K}$ in the $12-\mu \mathrm{m}$ channel of AATSR. Since the original study, more collocations have been added and it is now found that IASI agrees with AATSR at $11 \mu \mathrm{m}$ to an accuracy of better than $0.1 \mathrm{~K}$ with a bias of $-0.04 \pm 0.04 \mathrm{~K}$ for clear-sky scenes.

Intercalibration between IASI and AIRS, a hyperspectral sounder flying in the 1330 LT orbit on National Aeronautics and Space Administration's (NASA's) Earth Observing System (EOS) Aqua satellite, is especially important for climate applications, because between them they can provide information about Earth's diurnal cycle. Figure 4 shows AIRS-IASI SNO brightness temperatures and also a DD intercomparison (see the figure caption for more information). In general, both techniques show agreement to better than $0.2 \mathrm{~K}$, which is well below the specifications of both instruments. Time series analysis suggests that any radiometric drift between IASI and AIRS is at the milli-Kelvin level or smaller.

Dedicated calibration/validation (cal/val) campaigns. The Joint Airborne IASI Validation Experiment (JAIVEx; http://cimss.ssec.wisc.edu/jaivex/) was conducted in the United States in April-May 2007, coordinating flights of UK and U.S. atmospheric research aircraft collocated with overpasses of the MetOp-A satellite. Aircraft interferometer measurements confirmed calibration accuracy to better than $0.3 \mathrm{~K}$ (Newman et al. 2008; Larar et al. 2010). The measurements made during JAIVEx were also exploited to provide an independent estimate of the instrument noise by Masiello et al. (2011), who used a method based on the variance of spectral residuals between the observed 
and modeled radiances from the $\triangle$-IASI physical inversion scheme (Masiello et al. 2009) to demonstrate a high level of consistency with prelaunch estimates of level $1 \mathrm{c}$ noise.

A dedicated campaign organized by CNES in Brazil during June 2008 performed measurements using the IASI balloon (http://ether.ipsl.jussieu.fr /etherTypo/index.php?id=|283\&L=I) instrument (Té et al. 2002) with a MetOp-A simultaneous overpass. The IASI balloon is a stratospheric balloonborne interferometer with a higher spectral resolution than that of IASI, designed for in-orbit calibration of IASI and to test retrieval algorithms for certain trace gases. Using the Laboratoire de Probabilités et Modèles Aléatoires (LPMA) Atmospheric Retrieval Algorithm (LARA; Keim et al. 2009), the campaign demonstrated consistency of retrieved $\mathrm{CO}$ products and confirmed the good performance of IASI for performing retrievals of minor atmospheric constituents.

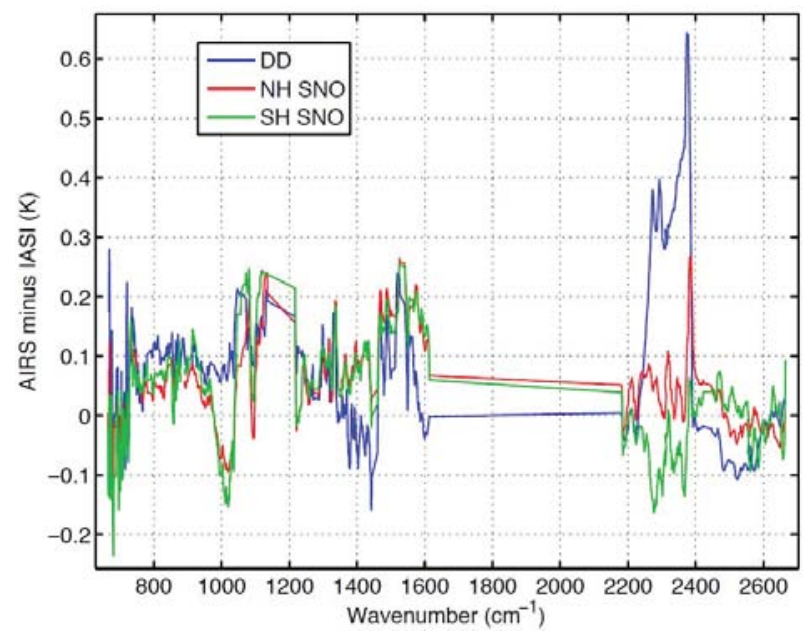

FIG. 4. AIRS-IASI SNO radiance in brightness temperature (BT) units for both the Northern Hemisphere (red) and Southern Hemisphere (green) SNO locations, smoothed over wavenumber to remove channelby-channel variations that result from inaccurate spectral calibration of both sensors. In blue is the DD intercomparison, which is the BT bias of AIRS minus the $B T$ bias of IASI, where the bias is the observed radiance minus the radiance computed from the ECMWF NWP forecast/analysis data. The DD technique removes almost all sensitivity to NWP model errors and radiative transfer errors and allows observations to be compared over a much wider geographical range than the SNO technique. Only clear, ocean FOVs are used in this study. The largest disagreement in the $2300 \mathrm{~cm}^{-1}$ region is actually very small because these very cold radiances are near the noise level for IASI. The dip in the SNOs near $1000 \mathrm{~cm}^{-1}$ is not reflected in the DD results and is not understood at this time.
Scene heterogeneity and subpixel cloud. Scene heterogeneity within a field of view (such as partial cold cloud cover over a warm background) can have a fundamental effect on the measurement by slightly altering the nominal instrument spectral response function. For an interferometer such as IASI, changing the angular distribution of rays entering the instrument will be discernible mainly by a shift in the wavelength to which each channel is sensitive. However, extensive analyses by A. Gambacorta et al. (2010, unpublished manuscript) have shown that the impact on the measured radiance is generally well below the level of instrument noise, and does not correlate with errors in retrieved products.

Understanding scene heterogeneity is also important for accurate forward modeling. At the present time, for many applications it is common to avoid using observations or parts of the spectrum that may be affected by subpixel cloud, which can be hard to detect. Work is ongoing to understand the effects and characteristics of subpixel cloud, in particular using the statistics of MetOp AVHRR observations that fall within the IASI field of view, and to assess the potential of methods such as cloud clearing (e.g., Li et al. 2005; Goldberg et al. 2003; Prunet et al. 2007), which attempt to separate the different components within a partially cloudy scene and increase the amount of usable information in the spectra.

Spectroscopy. Almost all of the applications of IASI, and indeed instrument calibration and validation studies, require synthetic radiances to be computed using radiative transfer models, which themselves depend on knowledge of the underlying spectroscopy of the atmospheric species that absorb and emit radiation at infrared wavelengths. The creation and maintenance of comprehensive databases of the absorption features of these gases, such as Gestion et Etude des Informations Spectroscopiques Atmosphériques (GEISA) IASI (http://ether.ipsl.jussieu.fr; Jacquinet-Husson et al. 2003, 2005, 2008, 2011) and High Resolution Transmission (HITRAN; Rothman et al. 2009), is therefore critical to the application of IASI data. GEISA currently covers the absorption features of 27 different atmospheric gases within IASI's spectral range. IASI has demonstrated an impressive ability to detect trace gas species and aerosol signatures, including some that were not expected prior to launch, which highlights the need to continue to extend and improve spectroscopic databases to realize the full potential of the instrument.

IMPACT OF IASI IN NWP. The primary goal of the IASI mission is to provide atmospheric emission/ 
absorption spectra to estimate temperature and humidity profiles with high resolution and accuracy for numerical weather prediction. The accuracy of the weather forecast depends critically on the accuracy of the initial state of the atmosphere, which is propagated forward in time to give the forecast. To create the best estimate of the initial state, observations are combined into the forecast model using data assimilation techniques, the most common of which is currently fourdimensional variational assimilation (4DVAR). Satellite sounding instruments, like IASI, are a crucial part of the global observing system for NWP, and over the last two decades have come to have the greatest forecast impact of any type of observation currently assimilated (e.g., Cardinali 2009).

For NWP, carbon dioxide absorption lines at 645$800 \mathrm{~cm}^{-1}(15.5-12.5 \mu \mathrm{m})$ are used to provide information primarily about the atmospheric temperature; the window region at $800-1,200 \mathrm{~cm}^{-1}(12.5-8.3 \mu \mathrm{m})$ contains information about the surface temperature and near-surface water vapor; and water vapor lines in the $1,200-1,600 \mathrm{~cm}^{-1}(8.3-6.3 \mu \mathrm{m})$ range add information on the vertical distribution of humidity. The large number of channels, high spectral resolution, and low radiometric noise of IASI mean that much more information about the atmospheric structure is available than from previous operational sounders (Amato et al. 1997; Prunet et al. 1998; Collard 1998). With improvements in the vertical resolution of forecasting models, the higher-resolution information from IASI spectra is becoming increasingly important.

The data from IASI were made available to NWP centers within 6 months of the launch of $\operatorname{MetOp}-A$, enabling centers to start using the observations for operational forecasting very quickly. The data are now used operationally at the majority of worldwide forecasting centers with advanced data assimilation schemes. Good instrument performance is critical in operational NWP, and IASI has provided a timely, reliable flow of high-quality, stable data. To date there has been no need for intervention in the assimilation system to prevent forecast degradation, which is sometimes required when the quality of an observation drops.

Operational assimilation. Tests of the performance of IASI within the forecasting system have shown positive impact at least as great as for any previously introduced new instrument (Hilton et al. 2009a; Collard and McNally 2009; Hilton et al. 2009b). Strong impacts have been found on geopotential height and mean sea level pressure, among other variables, out to 5-6 days, and Fig. 5 shows typical 
results from the Met Office. Although the RMS forecast error is not reduced for all variables, the overall performance is clearly positive. The impact scores in global models have been particularly impressive because IASI is assimilated into a system that is already very well observed by sounding data, with around 10 microwave and 5 additional infrared sounders. In particular, the benefits have been seen of having a hyperspectral sounder in both morning and afternoon orbits, because there is impact from combining IASI in the 0930 LT orbit with AIRS in the 1330 LT orbit. IASI observations are increasingly used in limited area models and have shown a positive impact, including on forecasts of precipitation, in convective-scale models with $1.5-2.5-\mathrm{km}$ horizontal resolution (Guidard et al. 2011). Current operational assimilation schemes for IASI are relatively conservative. They use up to only 200 channels, which are carefully chosen from the spectrum to maximize the information content of the observations (Collard 2007), because operational timing constraints mean
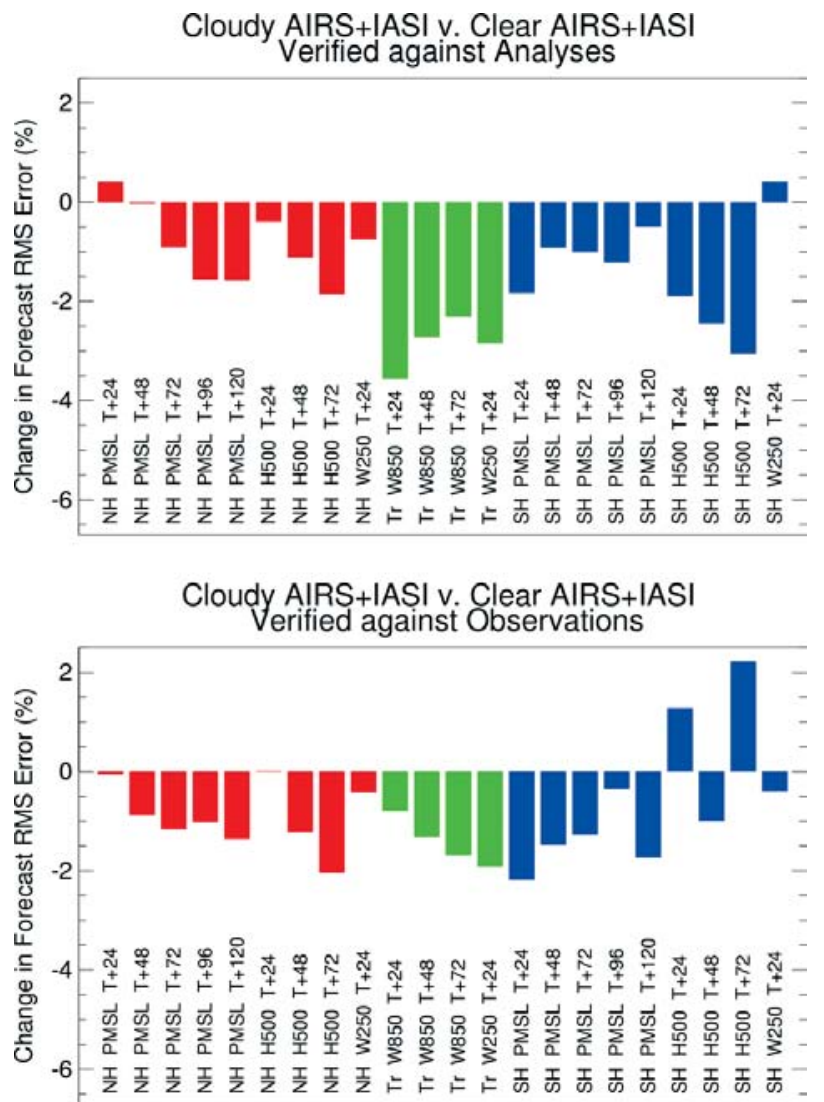

Fig. 6. Impact on Met Office RMS forecast error of assimilating channels down to cloud top from AIRS and IASI relative to assimilating clear scenes only. Statistics are for forecasts from I to 3 I Dec 2008. The different variables are displayed on the $x$ axis and are the same as in Fig. 5. that assimilating many more channels is too computationally expensive. Current data usage in the polar regions and large parts of the Northern Hemisphere is still rather low because of a lack of knowledge of the surface properties over land and sea ice; progress in this area is being aided by the development of surface emissivity atlases (discussed below in the context of climate). Of particular interest in current NWP research is the extraction of more information from each assimilated observation, particularly near the surface and on fine vertical scales.

Cloudy fields of view. Most centers assimilate channels where the effect of cloud in the field of view can be simulated using a simple cloud model. A common technique is either to assimilate channels with weighting functions that peak above a diagnosed cloud top (e.g., McNally and Watts 2003; Pavelin et al. 2008; Pangaud et al. 2009), or to use fully overcast scenes (McNally 2009). The channels above the cloud top provide important information to the forecast model, as shown in Fig. 6, which shows the impact on the Met Office RMS forecast error of the Pavelin et al. (2008) cloudy assimilation scheme relative to the assimilation of only completely clear observations. A recent study by Lavanant et al. (2010) compared the output of several operational cloud retrieval schemes for IASI and found that they show reasonable agreement for thick, overcast cloud layers and for high cloud. However, the ability to analyze complex multilayer cloud situations correctly is less reliable, and accounting for these cases this is still an active area of research. Work is also ongoing to develop more advanced schemes to make better use of cloud-affected data (e.g., Stengel et al. 2010; Guidard et al. 2011), but significant progress in this area is reliant upon developments in data assimilation schemes, radiative transfer models, and NWP models themselves.

Water vapor. The assimilation of most sources of satellite sounding data currently has little effect on humidity profiles in the boundary layer or on fine vertical structures. There are numerous factors that make assimilation of humidity information difficult, such as ambiguity arising from water vapor channel sensitivity to both temperature and humidity, nonlinearity of the instrument response to the amount of water vapor present, and high spatial variability of the water vapor concentration. These issues make it a challenge for linear assimilation algorithms to handle the observations correctly if the model state is too far from the true atmospheric state. 
At present, only a very few $(<40)$ IASI channels sensitive to water vapor molecules can generally be assimilated in NWP systems before the fit of the model to other observations and the numerical stability of the assimilation algorithm suffers (resulting in nonconvergence or giving physically unrealistic values). To enable their assimilation, humidity sounding channels are usually assumed to have much larger errors than can be attributed to the instrument noise, and this restricts their impact on the humidity profile. Research into the particular problem of the assimilation of IASI water vapor channels is being conducted at several operational centers. At the Met Office, the effort is directed toward understanding the error characteristics of the forecast model, which have a profound influence on the use of observations (Eyre and Hilton 2010; Hilton and Eyre 2010). Various practical measures are also being sought, and under current investigation at Météo-France is dynamic channel selection, where channels are chosen for each observation depending on the fit of each channel to the model forecast. Results using case studies from the JAIVEx campaign have shown that significantly more humidity information can be extracted from IASI using this technique.
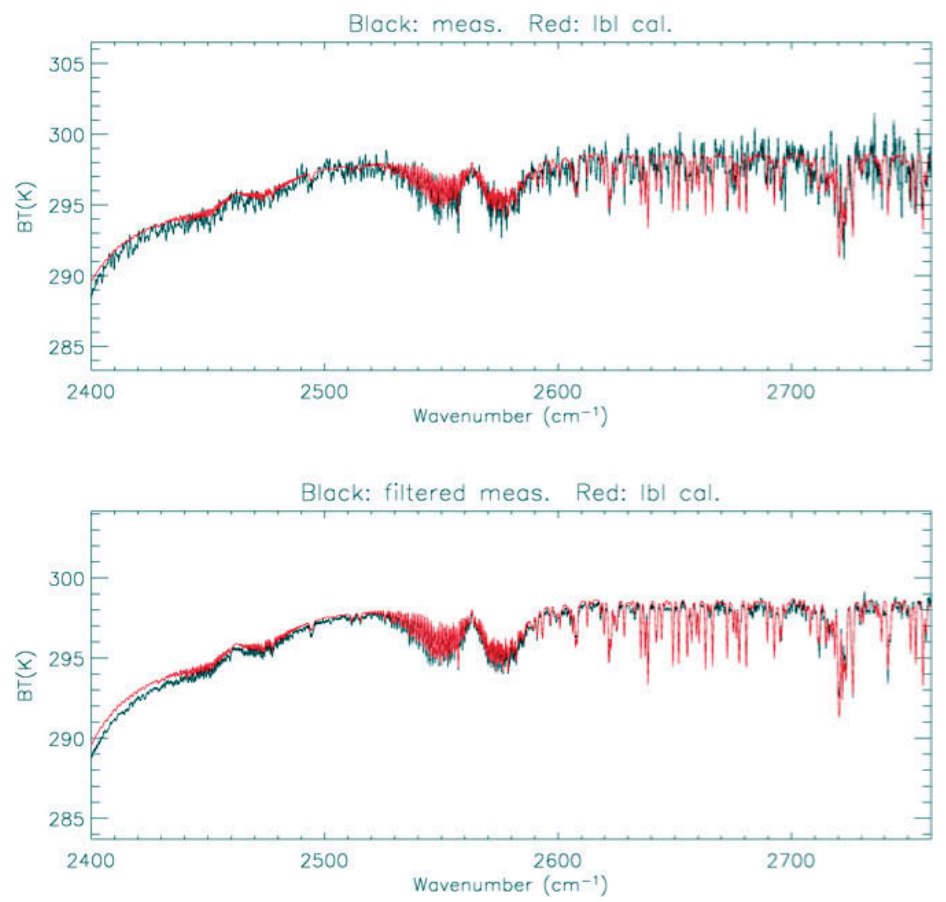

FIG. 7. The effect of principal component compression on spectral random noise. (top) A comparison of a simulated IASI spectrum from a line-by-line (LBL) radiative transfer calculation (red curve) with an observed spectrum (black curve). The radiative transfer calculation used a 6-h NWP forecast representative of the observed IASI measurement. (bottom) The LBL calculation plotted with the PCA-reconstructed "filtered" brightness temperatures. Note the high noise of the black curve in the upper plot, while the reconstructed and the LBL values are more similar in the lower plot because the noise has been filtered.
Principal components. There are potential benefits to using a larger proportion of the IASI spectrum. Principal component analysis (PCA) has received a great deal of attention both as a means for compressing hyperspectral data and in NWP-related retrieval algorithms (e.g., Aires et al. 2002; Masiello and Serio 2004; Liu et al. 2009). PCA exploits the redundancy of information in a dataset by performing a transformation to a new, uncorrelated set of variables (the PCs), where the first PC represents the spectral feature with the most variance, the second PC represents the feature with the second most variance, and so on. Retaining just the first few hundred components preserves the majority of the spectral information, and the remaining components, consisting mostly of random instrument noise, may be discarded without significant loss for many applications. Figure 7 shows an example of PC noise reduction in the IASI shortwave band.

Reliable, fast radiative transfer models exploiting PCA are now available (e.g., Liu et al. 2006) meaning that, in principle, $\mathrm{PC}$ compression could be used in operational NWP to allow the use of information from the full spectrum, rather than just the selected channels. There are difficulties in the practical use of PCs (Collard et al. 2010), but the feasibility of retrieving temperature and humidity profiles coupled with land surface emissivity from PCs has been demonstrated (Liu et al. 2009; Thelen et al. 2010) and work is now underway to test the use of PC-compressed spectra in an operational context.

Use of interferometric radiances. Grieco et al. (2010, 2011) analyze potential improvements in IASI products that can be achieved by using IASI interferograms directly, instead of IASI spectra. Like PC compression, interferometric radiances (obtained by selectively truncating the interferogram) provide a way of reducing data volume while retaining atmospherically important information. The use of the interferogram instead of sparsely selected individual channel radiances yields better water vapor retrievals, in terms of vertical resolution and accuracy. The 
concept of the partial interferogram is also relevant to atmospheric chemistry studies, where it can be exploited in the retrieval of gas species with absorption lines that are regularly spaced in the spectrum (such as $\mathrm{CO}_{2}$ or $\mathrm{CO}$ ) by using the truncation process to extract and isolate the lines of interest, minimizing the effects of the surface and other gases. Figure 8 illustrates the case of $\mathrm{CO}_{2}$, where the periodic nature of the emission lines produces a distinct feature in the interferogram. Grieco et al. (2011) demonstrate the ability to retrieve $\mathrm{CO}_{2}$ columns to within $\pm 7 \mathrm{ppmv}$ for a single IASI pixel, and their retrievals achieve better agreement with in situ measurements from the JAIVEx campaign than the AIRS-based European Centre for Medium-Range Weather Forecasts (ECMWF) analyses.

Ozone. Many NWP models now contain limited modeling of ozone for air quality forecasting and improved model physics. Ozone is also important to the assimilation system, because many infrared channels that could be used for temperature sounding are weakly affected by the gas. Han and McNally (2010) report on recent experiments at ECMWF to assimilate IASI channels at the frequencies of strong ozone absorption lines. IASI observations, which have the advantage that they can measure ozone at night, were found to have as strong an impact on the system as
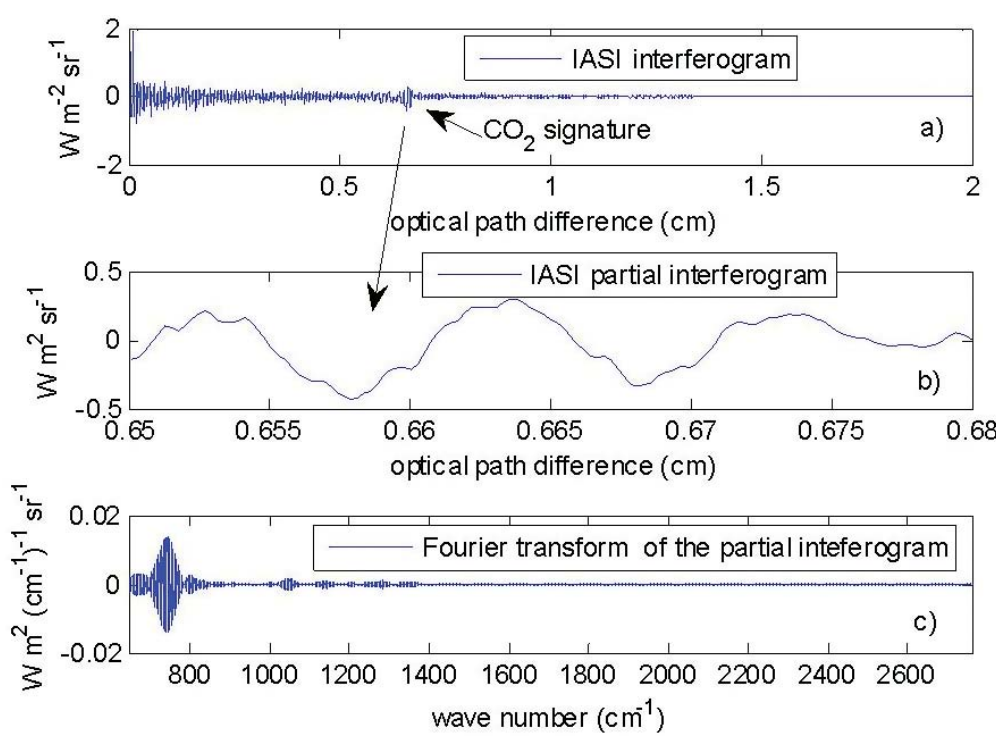

Fig. 8. The use of the partial interferogram to isolate $\mathrm{CO}_{2}$ emission lines from surface effects and other gas emissions. (a) A typical IASI interferogram. The periodic signature of $\mathrm{CO}_{2}$ is indicated (arrow). (b) Zoom in on the $\mathrm{CO}_{2}$ interferometric signal. (c) The result from when the partial interferogram is transformed back to the spectral radiance domain, leaving only the contribution to the spectrum from the $\mathrm{CO}_{2}$ lines: all other contributions have been removed (see Grieco et al. 20 II for details). dedicated visible and ultraviolet ozone instruments, and the assimilation of the IASI ozone channels improved the fit to stratospheric temperature sounding IMPACT OF IASI ON ATMOSPHERIC
COMPOSITION STUDIES. The second main objective of the IASI instrument is to provide data for atmospheric composition monitoring. Importantly, IASI meets the Global Climate Observing System (GCOS) climate monitoring principles (www.wmo.int/pages/prog/gcos/index.php?name= ClimateMonitoringPrinciples) because several flight models have been designed to allow a continuity of observations. IASI has provided major advances in the measurement of trace gases and aerosols (Clerbaux et al. 2009, and references therein), which are key for tackling environmental issues. In particular, research has shown that the excellent signal-to-noise ratio and good spectral resolution of IASI allows the retrieval of vertical profiles of trace gases that are comparable, or superior, to those of previous instruments. For $\mathrm{O}_{3}$ and $\mathrm{CO}$, IASI has demonstrated a potential impact on air quality forecasting and provides a continuation of the long-term chemical records of interannual variability that were started with other instruments. In addition, IASI has made it possible to measure concentrations of some reactive species that were thought to be undetectable from space, such as ammonia (Clarisse et al. 2009). IASI can also be used for near-real-time detection of events, such as fires and volcanic plumes.

Trace gas monitoring. Atmospheric chemistry studies with IASI rely on the retrieval of trace gas concentration distributions on various scales, from local (source monitoring) to regional (continental/intrahemispheric pollution) and global. One of the challenges for most applications is to deal with the huge data flow in near-real time, and to provide concentration measurements above sea and land surfaces, possibly also in partly cloudy conditions.

Operational trace gas products are available from EUMETSAT, mostly based on neural network retrieval schemes (Schlüssel et al. 2005; Ricaud et al. 2009). Preliminary evaluation of $\mathrm{O}_{3}$ and $\mathrm{CO}$ total columns (version 


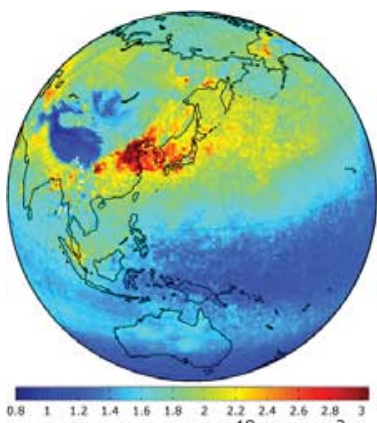

CO Total Column $\left(10^{18} \mathrm{~mol} / \mathrm{cm}^{2}\right)$

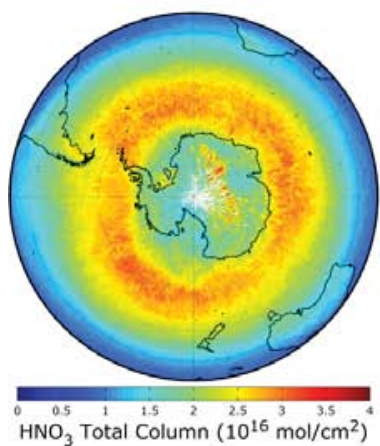

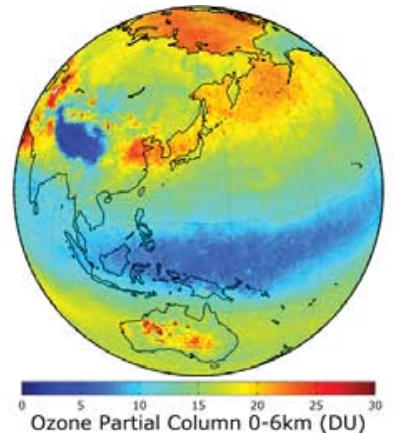

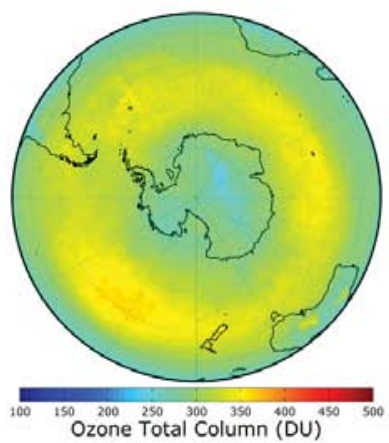

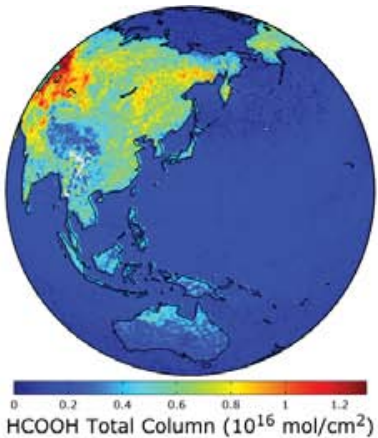

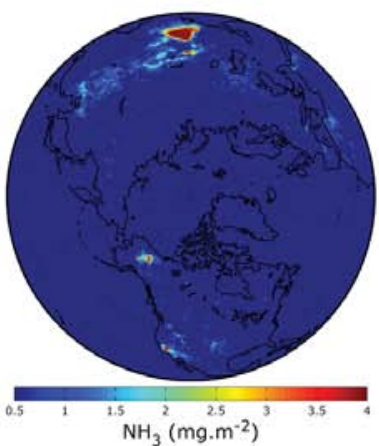

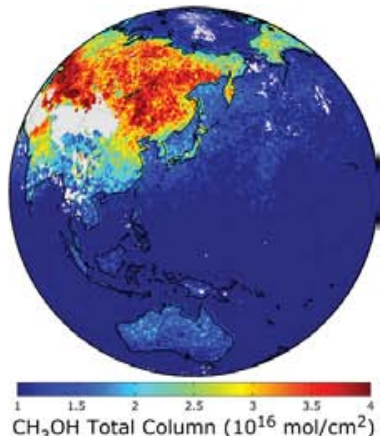

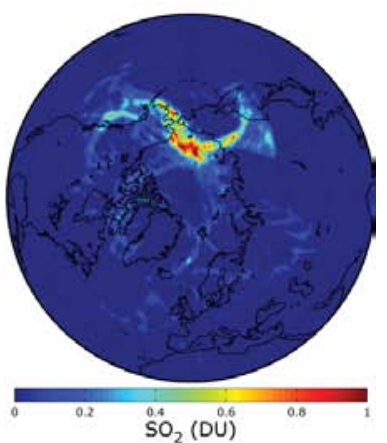

FIG. 9. Trace gas distributions retrieved from IASI spectra, averaged over I month of observations in Jul 2008. (top) Total columns for the chemistry gases carbon monoxide, ozone (tropospheric column), formic acid, and methanol. (bottom left) Polar projection over the Antarctic of ozone and nitric acid total columns, prior to the development of the ozone hole. (bottom right) Arctic projection showing hotspots of ammonia over continental areas and the $\mathrm{SO}_{2}$ plume following Okmok eruption.

5) with independent measurements and other products has shown good agreement overall. Comparisons of IASI ozone columns with Global Ozone Monitoring Experiment (GOME)-2-derived values show a bias of $2.7 \%$ (IASI higher) and a standard deviation of $2.5 \%$. CO columns have been compared to those from Measurements of Pollution in the Troposphere (MOPITT) on the Terra platform, where the standard deviation is between $8 \%$ and $15 \%$, depending on latitude (lower values in tropical regions). The bias is $10 \%$ (MOPITT is higher). EUMETSAT greenhouse gas products await further validation studies. NOAA also distributes its own operational trace gas products (see www.star.nesdis.noaa.gov/smcd/spb/iosspdt /iosspdt.php).

In parallel, efforts are made by the scientific community to provide IASI chemistry products with full characterization (vertical sensitivity functions and errors). Near-real-time global distributions of trace gas columns and/or vertical profiles are available from the Université Libre de Bruxelles (ULB)/Laboratoire Atmosphères, Milieux, Observations Spatiales
(LATMOS) processing chains, which combine a fast and accurate radiative transfer model with retrieval schemes based on the optimal estimation method. Global distributions are retrieved twice a day for $\mathrm{CO},{ }^{2}$ $\mathrm{O}_{3}$, and nitric acid $\left(\mathrm{HNO}_{3}\right)$, within 3-4 h of the observation (Fig. 9). They are provided as weakly resolved vertical profiles, with the number of independent pieces of information for each gas depending mostly on the thermal state of the atmosphere (one-two for $\mathrm{CO}$ on 19 tropospheric levels, three-five for $\mathrm{O}_{3}$ on 40 levels up to $0.1 \mathrm{hPa}$, and one for $\mathrm{HNO}_{3}$ ). Several other dedicated research algorithms are available in the science community; in particular, for distributions of tropospheric $\mathrm{CO}$ and $\mathrm{O}_{3}$. These trace gas distribution products have led to some important results for atmospheric chemistry.

CARBON mONOXIDE (CO). Carbon monoxide, with a chemical lifetime of several weeks in the troposphere, is an excellent tracer of atmospheric pollution. Its atmospheric concentration can be used to infer critical information on pollution transport and carbon

\footnotetext{
${ }^{2}$ CO columns from the Fast Optimal/Operational Retrieval on Layers for IASI (FORLI) suite can be accessed via the Ether database (http://ether.ipsl.jussieu.fr). CO quick-look daily maps can also be viewed with different projections from LATMOS (http://iasi-chem.aero.jussieu.fr).
} 
emissions. IASI CO columns have been shown to agree well with retrievals from the other infrared sounders, such as the Thermal Emission Spectrometer (TES), AIRS, and the MOPITT instrument. In particular, both local (Illingworth et al. 2011a) and global studies (George et al. 2009) have thus far indicated very good agreement with MOPITT versions 3 and 4 data, with average systematic biases in total columns of $10 \%$ or less, and allow IASI to continue MOPITT's record of seasonal and interannual variability. CO columns are now assimilated operationally at ECMWF in the Global Monitoring for Environment and Security (GMES)/Monitoring Atmospheric Composition and Climate (MACC) forecasting model to produce a chemical forecast of CO fields, and are also used in a variational Bayesian system to infer the global distribution of CO emissions (Fortems-Cheiney et al. 2009). They have also served as reference for the Polar Study using Aircraft, Remote Sensing, Surface Measurements and Models, of Climate, Chemistry, Aerosols, and Transport (POLARCAT) International Polar Year (IPY) activities to plan aircraft campaigns and to study the transport of pollution plumes from boreal fires moving toward the Arctic (Pommier et al. 2010; Sodemann et al. 2011).

OzONE $\left(\mathrm{O}_{3}\right)$. As mentioned in the context of NWP, IASI radiances contain information on the $\mathrm{O}_{3}$ profile and several centers produce standalone $\mathrm{O}_{3}$ products.

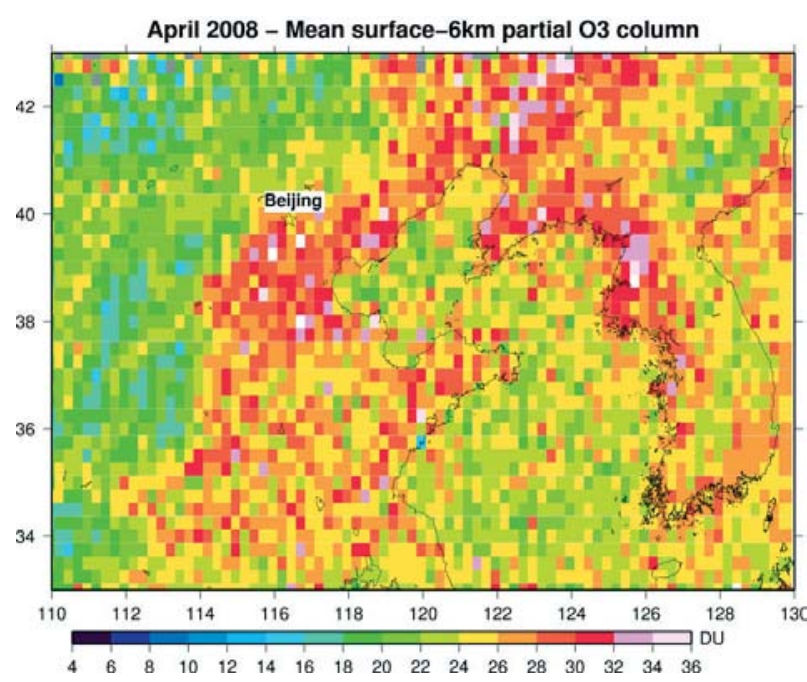

FIG. 10. Tropospheric ozone distributions in Dobson units (DU), shown as partial columns from the ground to $6 \mathrm{~km}$, above China for the month of Apr 2008. Note that the sensitivity to the lowest layers of the troposphere varies with the thermal contrast. As a result, the pixels do not represent exactly the same vertical distribution, with enhanced sensitivity to the lower troposphere over land compared to over ocean.
Validation studies have already been performed using local sonde measurements or GOME-2 data, and by comparing different algorithms the excellent capabilities of IASI have been largely confirmed (Boynard et al. 2009; Keim et al. 2009). Most importantly, stratospheric and tropospheric distributions can be separated and studied almost independently (Boynard et al. 2009; Eremenko et al. 2008). In the stratosphere IASI provides a remarkable view of the ozone hole and its structure, even during the polar night, which is promising for the investigation of processes related to ozone hole development and for monitoring the expected recovery of the ozone layer following the Montreal Protocol (UNEP 2009). In the troposphere, the focus is on air quality monitoring, stimulated by early studies that showed IASI's sensitivity to pollution events (Eremenko et al. 2008). Tropospheric ozone distributions have recently been analyzed over several megacities in China and other parts of the world, and the large ozone amounts that are found (Fig. 10) suggest an anthropogenic origin (Dufour et al. 2010). The seasonal variation of tropospheric ozone in China also shows the influence of the Asian monsoon and suggests that large ozone concentrations can be due to the descent of ozone-rich air from the stratosphere (e.g., during the winter in Beijing). The assimilation of tropospheric ozone fields in regional chemical transport models has now started and shows promise for air quality applications (Foret et al. 2009). The study of the upper troposphere-lower stratosphere (UTLS) region, which is crucial for assessing the impact of ozone on radiative forcing, can also be undertaken with IASI.

NitRIC ACID $\left(\mathrm{HNO}_{3}\right)$. IASI provides unprecedented information on the global distributions of $\mathrm{HNO}_{3}$ columns. Preliminary studies have an emphasis on spatial and seasonal variability and on the role of nitric acid in the development of the ozone hole (Wespes et al. 2009). Because IASI's sensitivity to $\mathrm{HNO}_{3}$ is mainly in the UTLS region, there is great interest in using the retrieved distributions to constrain estimates of the production of $\mathrm{NO}_{\mathrm{x}}$ by lightning.

AMMONIA $\left(\mathrm{NH}_{3}\right)$ AND VOLATILE ORGANIC COMPOUNDS. In addition to the main trace gases, IASI can detect emission sources of short-lived species. These species usually have very weak spectral signatures, and so currently simple radiance indexing methods based on brightness temperature differences are applied to produce global distribution maps (Clarisse et al. 2009; Razavi et al. 2011; Walker et al. 2011), with possible extension to the use of noise-filtered radiances (Atkinson et al. 2010). 
The first global distributions of $\mathrm{NH}_{3}$ reveal the principal hotspots resulting from agriculture and suggest, through a comparison with chemical transport models, significant underestimation of current emission inventories (Clarisse et al. 2009). This result is one of the highlights of the IASI mission since its launch. An example of the $\mathrm{NH}_{3}$ distribution above Europe is provided in Fig. 11. Local analyses using more sophisticated retrieval methods have recently demonstrated the capability of IASI to capture daily variations in the concentration of $\mathrm{NH}_{3}$ above hotspot regions (Clarisse et al. 2010a), providing opportunities to study the cycle of reactive nitrogen species in the atmosphere, and their impact

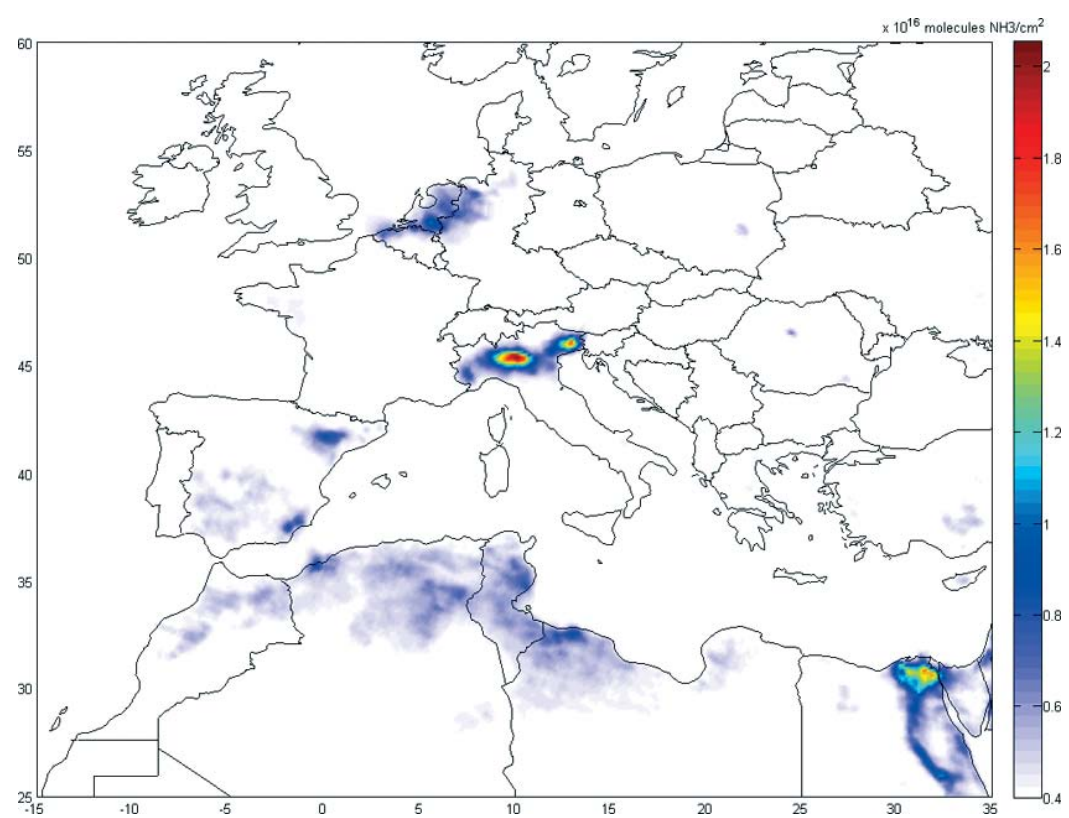

Fig. II. Ammonia distributions (total columns, in molecules per cubic centimeter) above Europe, averaged for Jun 2010 , on a $0.125^{\circ} \times 0.125^{\circ}$ grid. on ecosystem health and on cli-

mate. Using similar methods, global distributions of methanol $\left(\mathrm{CH}_{3} \mathrm{OH}\right)$ and formic acid $(\mathrm{HCOOH})$ total column amounts have been obtained and evaluated on a seasonal basis (Razavi et al. 2011). These strengthen the contribution of IASI to tropospheric chemistry monitoring and to the improvement of emission inventories from different sectors.

Near-real-time plume chemistry and tracking. With its broad spectral coverage of the thermal infrared, and excellent radiometric performance and horizontal sampling, IASI can track gaseous plumes released into the atmosphere after extreme events, such as volcanic eruptions and large fires (Fig. 12). Although limitations remain due to the polar orbit, which provides twice-daily sampling in comparison with quasi-continuous geostationary observations, this capability was not expected prior to launch. The tracking of plumes is based on the detection of the spectral signatures of short-lived gases, which are usually not seen in the radiance spectra because of the low abundance of the species but show up in these exceptional situations because of the marked concentration enhancements in the plumes.

Volcanic plumes are identified in IASI spectra based on the $\mathrm{SO}_{2}$ signal (see Fig. 12, top), largely from the $\bigotimes_{3}$ band around $1,350 \mathrm{~cm}^{-1}$, although several other bands can be used (Clarisse et al. 2008, 2010b; Karagulian et al. 2010). The detection of volcanic plumes has a straightforward application in aircraft safety (Rix et al. 2009). A radiance indexing method is applied in near-real time to alert users (e.g., Volcanic Ash Advisory Centers) to the presence of a highaltitude volcanic plume just $3 \mathrm{~h}$ after the measurements are taken. The location and extent of the plume is tracked in each subsequent MetOp overpass. An automatic operational alert system (http://cpm-ws4 ulb.ac.be/Alerts/) has been running since January 2008, which has proven to be extremely robust and valuable, identifying all major eruptions releasing $\mathrm{SO}_{2}$ while avoiding false alarms completely. The detection and monitoring of volcanic ash (Clarisse et al. 2010c) is described in the next section.

Fires are easily monitored using $\mathrm{CO}$ measurements (Turquety et al. 2009; Illingworth et al. 2011b), but source attribution remains uncertain in many cases because of other contributions to $\mathrm{CO}$ emissions from, for example, fossil fuel combustion. In large fires, volatile organic compounds and nitrogen species are released in significant amounts, and can be detected in the IASI spectra (Fig. 12). The combination of the signals from ammonia, formic acid, methanol, and sometimes ethene $\left(\mathrm{C}_{2} \mathrm{H}_{4}\right)$, alongside that of $\mathrm{CO}$, allow for the unambiguous identification of fires and the tracking of their plumes in space and time. The fate of these different species during transport also gives information on the chemistry processes in the plumes (Coheur at al. 2009). It is anticipated that the use of IASI will significantly improve the determination of emission ratios for several species. 
IASI'S CONTRIBUTION TO CLIMATE STUDIES. The results of validation studies outlined in "IASI performance and calibration" show that IASI has promise for climate applications. These studies are aimed at meeting the requirements expressed in the Global Climate Observing System (GCOS; www.wmo.int/pages/prog/gcos/) implementation plan for the generation of calibrated observations of essential climate variables (ECVs) from satellites and the generation of products for use in monitoring the global climate. IASI contributes to the study of several ECVs and other important climate datasets (Fig. 13). Examples include temperature and water vapor profiles (Pougatchev et al. 2009; Amato et al. 2009), cloud and aerosol properties, measurements of anthropogenic greenhouse gases $\left(\mathrm{CO}_{2}\right.$ and $\left.\mathrm{CH}_{4}\right)$ and ozone $\left(\mathrm{O}_{3}\right)$, and surface temperature and emissivity. Zhou et al. (2009) have demonstrated the ability to retrieve thermodynamic parameters from AIRS and IASI; the derived temperature and moisture profiles capture observed trends and field evolution when compared against coincident radiosonde, dropsonde, and aircraft interferometer measurements.

What is crucial for the GCOS programme is the construction of a homogeneous, robust long-term data record of climate variables. IASI has been providing data in an operational capacity for $5 \mathrm{yr}$, and thus has not yet made significant contributions to the analysis of long-term climate trends. However, the operation of two more IASI instruments on MetOp-B in 2012 and $\mathrm{MetOp}-\mathrm{C}$ in 2016 will yield at least $15 \mathrm{yr}$ of continuous observations. Thanks to this long time series and to its excellent radiometric stability, IASI will contribute significantly to the study of our climate, continuing the long time series of climate variables that began with HIRS on the NOAA satellite platforms, and then AIRS on NASA's EOS Aqua satellite.

Evaluation of IASI climate datasets is already underway, and the following sections present some of the achievements of IASI during its first $5 \mathrm{yr}$ of operation, and highlight areas where IASI is likely to play an important role in future studies.
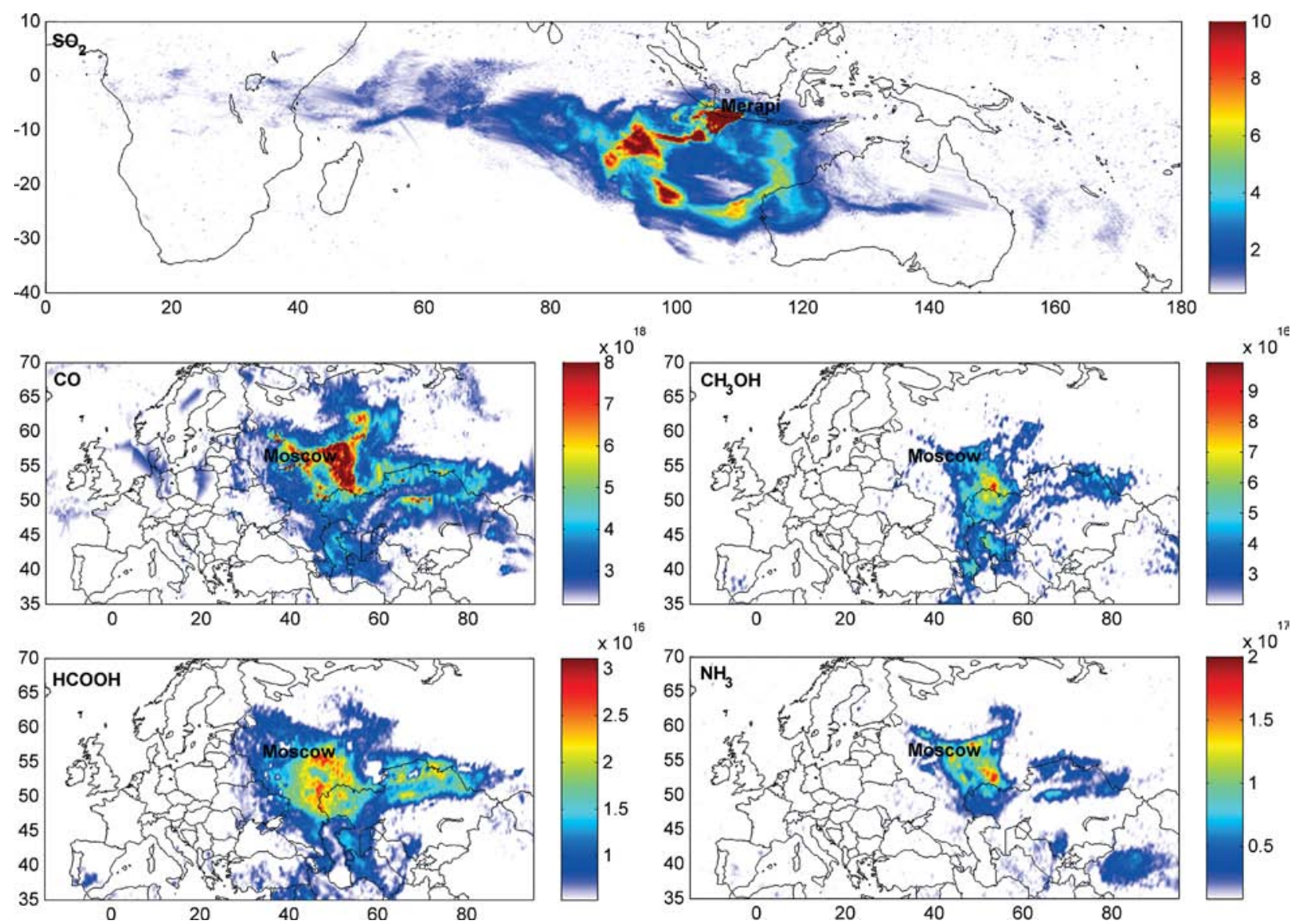

FIG. I2. (top) $\mathrm{SO}_{2}$ plume (DU) from the Nov 2010 Merapi eruption in Indonesia, integrated from 3 to 20 Nov. (bottom) Pollution plume from the central Russian fires in summer 2010, as observed with various trace gases. Note that for $\mathrm{CO}$ only values above $2.2 \times 10^{18}$ molecules $\mathrm{cm}^{-2}$ are plotted. 
The hydrological cycle. The IASI record already includes a large sample of climate variability events, such as the 2006 and 2009 El Niño/La Niña, intertropical convergence zone (ITCZ) oscillations, Madden-Julian oscillation (MJO) events, and volcanic eruptions. These phenomena are of great importance for studying the dynamic processes regulating hydrological variables and their sensitivity to surface temperature. Overall assessment of water vapor and cloud feedbacks, along with the determination of the sources and sinks of atmospheric hydrological variables, are still critical issues in climate science, mainly because of the historical lack of a comprehensive, robust, high vertical resolution database. The IASI instrument will be an unprecedented resource to help resolve these issues. The ability of IASI to probe the water isotopic composition adds a new dimension to the study of the hydrological cycle (Herbin et al. 2009).

Cloud properties. Clouds cover more than two-thirds of the Earth's surface and hence play a dominant role in the energy and hydrological cycle of our planet.
Compared to other passive remote sensing instruments, the high spectral resolution of hyperspectral infrared sounders such as IASI leads to especially reliable determination of cirrus properties, even where optical thickness is as low as 0.1 (e.g., Stubenrauch et al. 1999, 2010). An example of retrieved high cloud amount is given in Fig. 13a. Because infrared (IR) sounders do not introduce artificial day-night biases into retrievals of cloud properties, the data are very useful for studying the diurnal cycle (Fig. 13b). Figure $13 \mathrm{~b}$ reveals greater tropical high cloud amounts in the evening than in the morning, especially over convective land regions, which can be linked to cirrus (Stubenrauch et al. 2006).

IASI-derived cloud properties have been compared with various cloud climate data records also compiled in the Global Energy and Water Cycle Experiment (GEWEX; http://climserv.ipsl.polytechnique.fr Igewexca) Cloud Assessment. Figure 14 presents an intercomparison of zonal averages of high cloud amount. Despite differences in sampling and observation times, the latitudinal behavior of all datasets

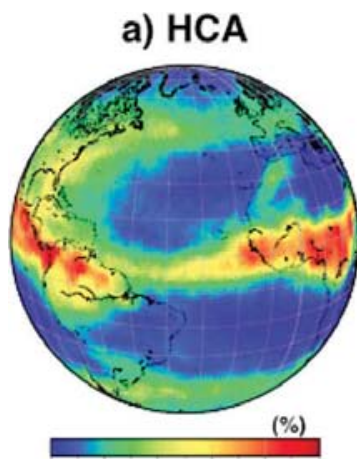

$\begin{array}{llllll}0 & 20 & 40 & 60 & 80 & 100\end{array}$
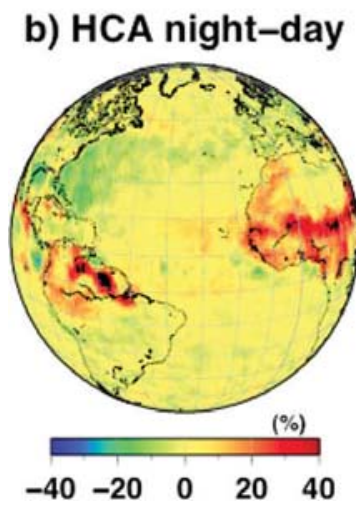

c) $\mathrm{CO}_{2}$

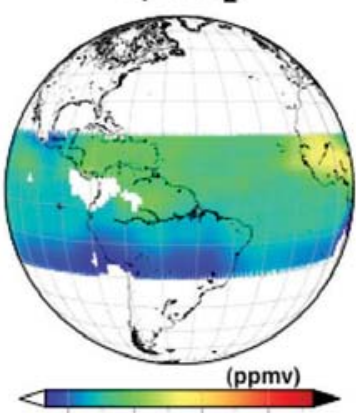

384387390393

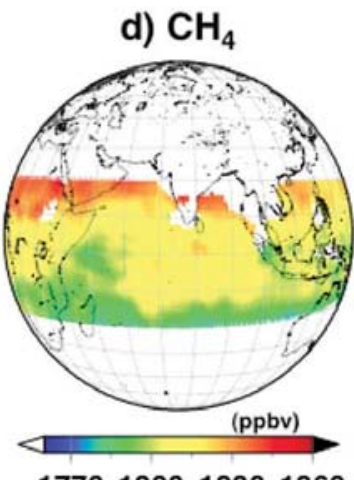

e) Dust AOD

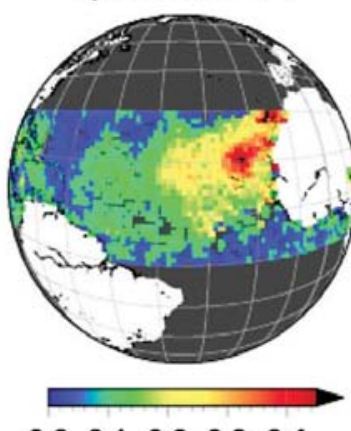

$\begin{array}{lllll}0.0 & 0.1 & 0.2 & 0.3 & 0.4\end{array}$
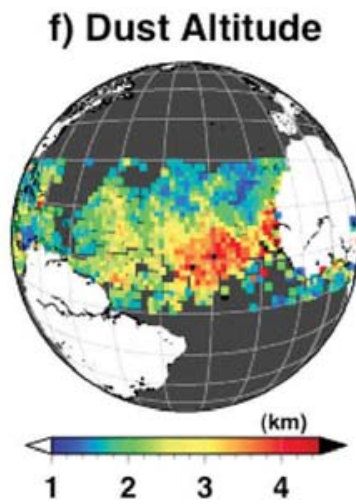

g) Surf. temperature

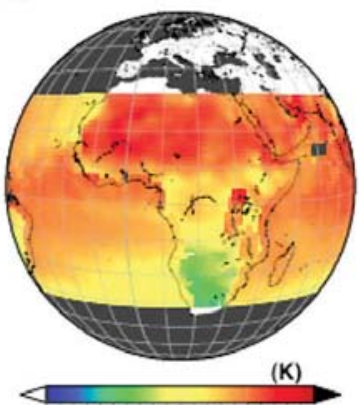

270280290300310

h) Surf. emissivity

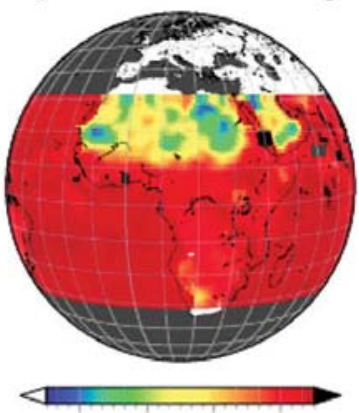

0.780 .840 .900 .96

FIG. I3. Geographical maps of some ECVs retrieved from IASI spectra: (a) high cloud amount (pressure < $440 \mathrm{hPa}$ ) for Jul 2008 during day; (b) night-day difference in high cloud amount for Jul 2008 showing interesting patterns in the ITCZ over land and the North Atlantic; (c) midtropospheric content of $\mathrm{CO}_{2}$ averaged over Jun-Aug for 2008; (d) as in (c), but for $\mathrm{CH}_{4}$; (e) dust AOD at $10 \mu \mathrm{m}$ for Jul 2008 ; (f) dust altitude for Jul 2008; (g) surface temperature for Jun 2008; (h) surface emissivity at $I, 227.00 \mathrm{~cm}^{-1}$ for Jun 2008. 


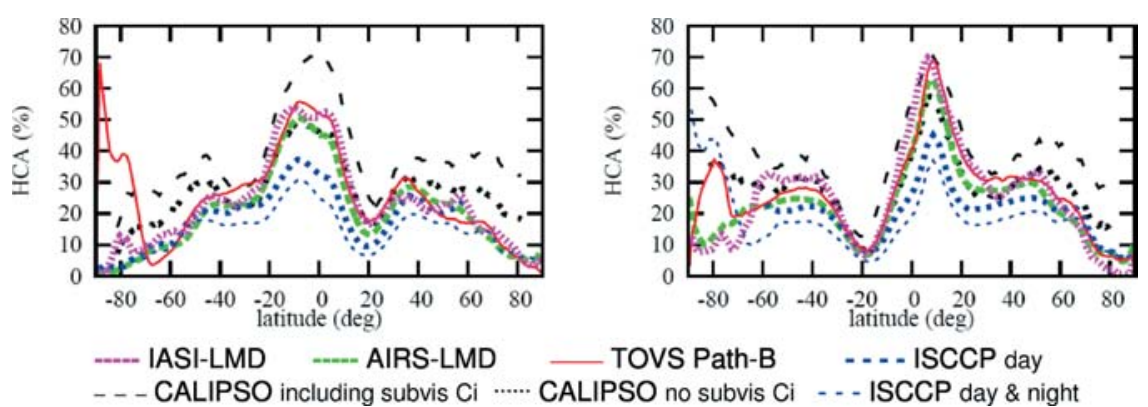

Fig. 14. Zonal averages of amount of high clouds from IASI compared to results from various cloud climate data records, in (left) Jan and (right) Jul. The datasets are AIRS-LMD (2003-08; Stubenrauch et al. 2010), CALIPSO (2007-08; Winker et al. 2009), TOVS Path-B products (1987-95; Scott et al. 1999; Stubenrauch et al. 2006), and ISCCP (1984-2007; Rossow and Schiffer 1999).

agrees reasonably well. Discrepancies in absolute values can be explained by the differing instrument sensitivities to thin cirrus. The active lidar of the Cloud-Aerosol Lidar and Infrared Pathfinder Satellite (CALIPSO) mission (Winker et al. 2009) is most sensitive to cirrus by design. The International Cloud Climatology Project (ISCCP; Rossow and Schiffer 1999), with emphasis on the diurnal cycle and using imagers with one visible (i.e., daytime only) channel and one infrared channel, identifies about $20 \%$ less high cloud in the tropics. The higher spectral resolution of IASI will be important for improving the retrieval of bulk microphysical properties of semitransparent cirrus when compared to instruments such as Television and Infrared Observation Satellite (TIROS) Operational Vertical Sounder (TOVS; Rädel et al. 2003).

The study of aerosols. Dust aerosol optical properties in the infrared are needed to evaluate the total radiative forcing of dust, which still remains one of the largest uncertainties in the current estimation of the Earth's radiative budget. Most remote sensing studies focus on the solar spectrum and take advantage of high spatial resolution instruments such as Moderate Resolution Imaging Spectroradiometer (MODIS). Infrared aerosol sounding has a number of advantages that complement observations made in the visible-good sensitivity to large particles, the ability to observe aerosols during both day and night, the possibility of retrieving altitude information together with optical depth and radius, and low dependency on particle shape and surface reflectance (Pierangelo et al. 2004, 2005). Because of its high spectral resolution, IASI enables the detection and quantification of various aerosol properties (Clarisse et al. 2010b) and can, in particular, differentiate between aerosol types based on their composition. For instance, even similar compositions, such as volcanic ash versus windblown sand, and different types of volcanic ash can be discriminated (Gangale et al. 2010; Clarisse et al. 2010a). Thus far, aerosol species detected with IASI include volcanic particles (sulfuric acid, volcanic ash, and volcanic ice), dust (sand or mineral dust storms), and combustion aerosols from biomass burning events.

Figures 13 e, f show dust infrared aerosol optical depth (AOD) and mean altitude from IASI, following the method previously developed for AIRS (Pierangelo et al. 2004; Peyridieu et al. 2010). Time series exploring the natural cycles of AOD in the Atlantic basin are also revealing the good agreement found between MODIS, AIRS (Peyridieu et al. 2010), and IASI. A comparison between IASI-retrieved mean altitude and Cloud-Aerosol Lidar with Orthogonal Polarisation (CALIOP) dust layer products has been performed using 2 yr of data (Peyridieu 2010). Near the dust sources, the average difference of the two products is around $240 \pm 490 \mathrm{~m}$ and illustrates the ability of IASI to retrieve accurate dust layer mean altitude. Preliminary retrievals of the effective radius of the dust coarse mode (Peyridieu 2010) also appear to be in good agreement with studies using either ground-based or in situ measurements. The retrieved dust effective radius ranges from about $2.3 \mu \mathrm{m}$ near the African coast to about $1.4 \mu \mathrm{m}$ in the Caribbean, in agreement with, for example, results of the Puerto Rico Dust Experiment (PRIDE) campaign (Maring et al. 2003).

Greenhouse gases. Despite the short time series available so far, IASI can already be used to study the trend in atmospheric carbon dioxide concentrations and the effect of this trend on the Earth's outgoing longwave radiation. The increase in atmospheric carbon dioxide is reflected in negative brightness temperature trends in the 690-750 and $2390-2400 \mathrm{~cm}^{-1}$ regions (among others). The power of IASI to see carbon dioxide time variability is shown in Fig. 15, which shows the relative change in carbon dioxide versus time using a single IASI channel $\left(791.75 \mathrm{~cm}^{-1}\right)$ and zonally averaged, ocean-only observations, between $0^{\circ}$ and $25^{\circ} \mathrm{N}$, as based on the method developed for AIRS by Strow 
and Hannon (2008). Although more robust results can be produced when several hundred channels are considered together, this preliminary figure shows an estimated increase of about $1.7 \mathrm{ppm} \mathrm{yr}^{-1}$ and peak-

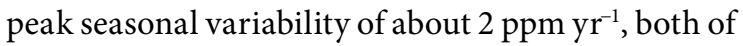
which are close to nominal in situ measurements.

The main difficulty in estimating the global distribution of $\mathrm{CO}_{2}$ from infrared sounders comes from the fact that infrared measurements are sensitive to both temperature and variations in gas concentration. Independent information on temperature, such as that which can be derived from the Advanced Microwave Sounding Unit (AMSU) instrument also on $\mathrm{MetO} p-A$, is needed to separate these two effects. Higher-quality retrievals are expected in the tropics because of the lower variability of temperature profiles compared to that of the extratropics.

Crevoisier et al. (2009a,b) present a stand-alone nonlinear approach based on neural networks to interpret the IASI-AMSU observations in terms of midtropospheric $\mathrm{CO}_{2}$ and $\mathrm{CH}_{4}$ integrated column amounts. This method was previously developed for interpreting TOVS (Chédin et al. 2003) and AIRS (Crevoisier et al. 2004) observations in terms of upper-tropospheric $\mathrm{CO}_{2}$. The precision of the retrieval is estimated to be about $2.0(0.5 \%)$ and $16(\sim 1 \%)$ ppbv, respectively for a $5^{\circ} \times 5^{\circ}$ spatial resolution on a monthly time scale. IASI provides evidence for several features of the $\mathrm{CO}_{2}-\mathrm{CH}_{4}$ space-time distribution (Figs. 13c,d) including information on the trends of increasing gas concentration, seasonality, and latitudinal variations. IASI also allows identification of sources of $\mathrm{CO}_{2}$ and $\mathrm{CH}_{4}$ emissions transported to the free troposphere, such as $\mathrm{CO}_{2}$ emissions from biomass burning, and elevated methane resulting from emissions from Asian rice paddies that are uplifted by deep convection during the monsoon period. It provides the means to study the correlation between $\mathrm{CO}_{2}$ and $\mathrm{CH}_{4}$, allowing us to observe and understand the atmospheric transport pathways of greenhouse gases from the surface to the upper troposphere.

Surface emissivity. Skin temperature and emissivity spectra are essential variables for climate studies, including the computation of total radiative budget, the study of land-atmosphere interactions, and their parameterization in climate models. Establishing an understanding of land surface properties is also of particular importance to atmospheric chemistry applications, where the sensitivity to species in the lower troposphere depends critically on the presence and knowledge of thermal contrast between the surface and lowest atmospheric layers. For NWP, tropospheric sounding channels, which would improve remote sensing of the lower atmosphere, are frequently rejected over land. This is due to their sensitivity to surface temperature and emissivity, which are often not specified by NWP models to the degree of accuracy required for assimilation.

IASI is an ideal instrument for studying surface emission because of its daily, global, and complete spectral coverage across the thermal infrared region. Several centers are now working on the creation of high spectral resolution emissivity atlases from IASI (e.g., Zhou et al. 2011; Capelle et al. 2012; see also http://ara.Imd.polytechnique.fr), providing monthly or weekly products that capture the natural variability of the Earth's surface and show clear evidence of seasonal variability associated with changes in surface weather and vegetation properties. Figure $13 \mathrm{~h}$ shows a weekly emissivity map from the atlas of Capelle et al. 2012. These atlases may be used directly, or in NWP they may provide a "first guess" emissivity, which can be modified during assimilation to match the properties of each observation. Figure 16 shows examples of two emissivity retrievals from the atlas of Zhou et al. (2011), which demonstrate IASI's ability to resolve the differing spectral properties of the surface; in particular, the quartz Reststrahlen band at $1,150-1,200 \mathrm{~cm}^{-1}$ for sandy desert.

Polar studies. The mass budget of the Antarctic ice sheet and its potential impact on global sea level is a critical issue for climate change studies. The Concordiasi field

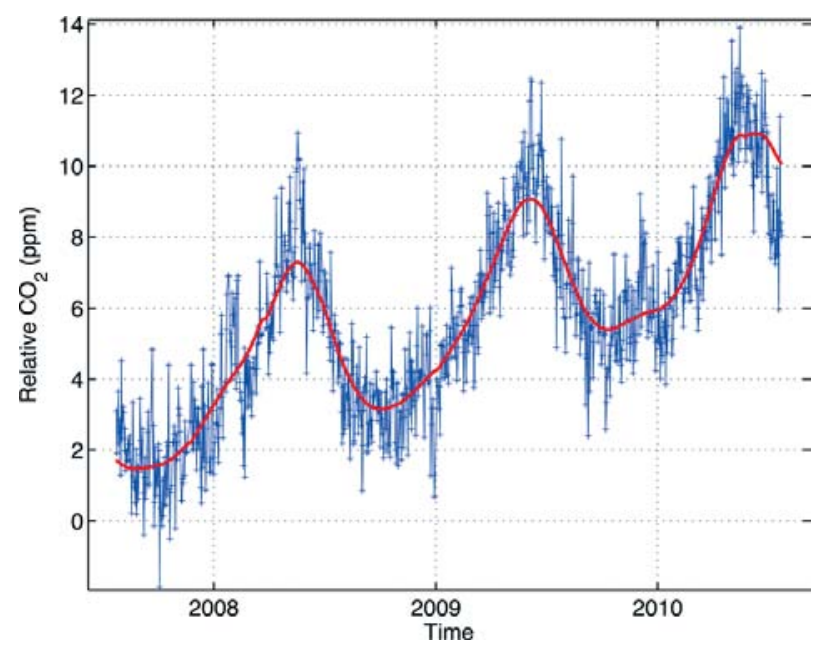

FIG. I5. Change in carbon dioxide versus time, derived from the IASI channel at $791.75 \mathrm{~cm}^{-1}$, for zonally averaged, ocean-only observations between $0^{\circ}$ and $25^{\circ} \mathrm{N}$.

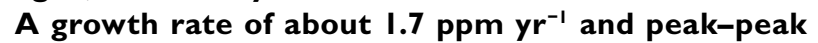

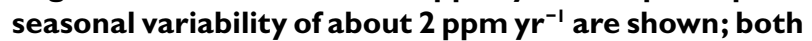
are close to nominal in situ measurements. 

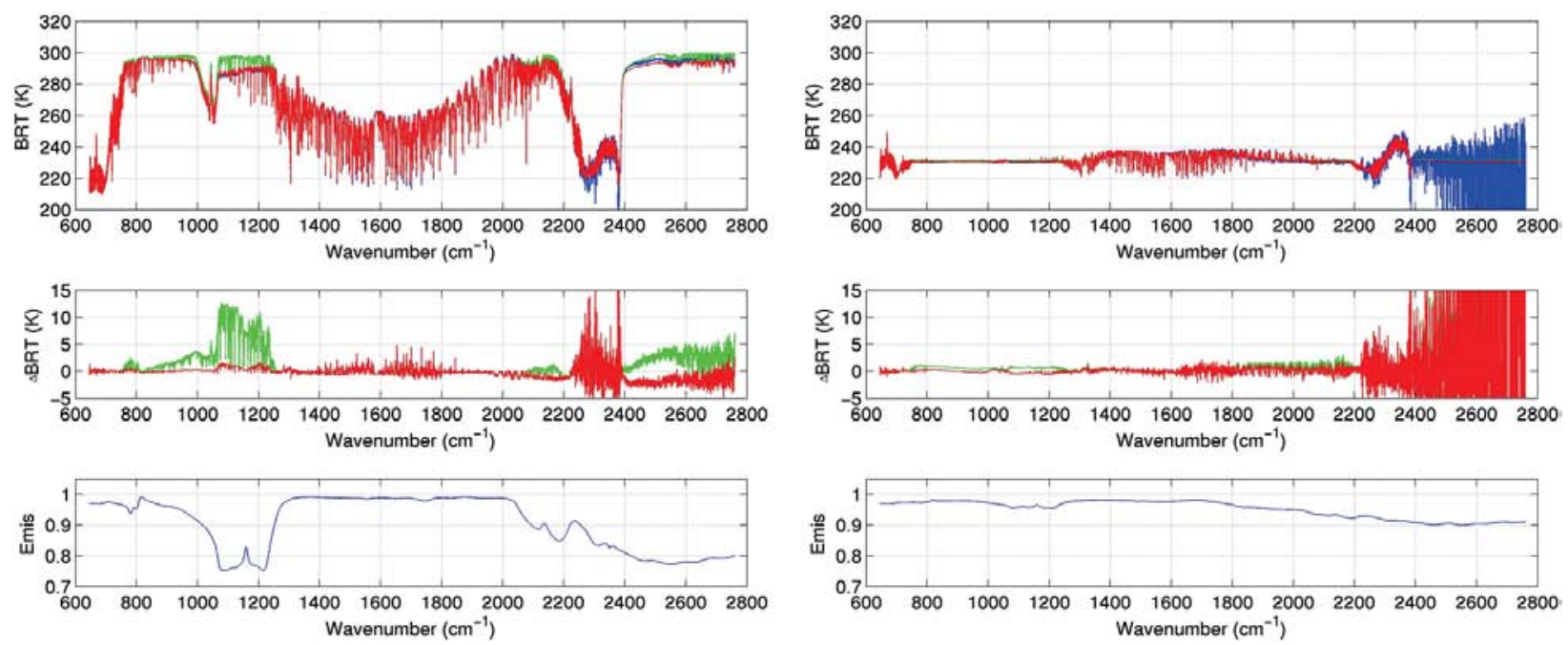

FIG. 16. Sample of retrieved spectral emissivity from IASI observations ( 15 Oct 2010) from the atlas of Zhou et al. (20II). (left) Sahara Desert (with Ts = 300.04 K) and (right) Polar Desert (with Ts = 230.34 K). (top) Measured brightness temperature spectrum (blue), simulated brightness temperatures using retrieved profiles (Zhou et al. 2009) and unity emissivity (green), and simulated brightness temperatures using retrieved profiles and retrieved emissivity (red) are shown. (middle) The difference between measured and simulated spectra using unity emissivity (green) and retrieved emissivity (red) is shown. (bottom) Retrieved emissivity.

experiment (Rabier et al. 2010) was set up to improve understanding of Antarctic conditions and the way they affect observations. One specific aim of the project is to improve climate reanalysis datasets, which are vital tools to assess the evolution in time of the precipitation distribution and other fields important to the mass budget of the ice sheet. Generating high-quality reanalyses requires that errors in the interpretation and use of hyperspectral infrared data are reduced. Bouchard et al. (2010) present some early results from the Concordiasi campaign and demonstrate improved retrievals of atmospheric profiles when the surface temperature is estimated using IASI itself (at $943.25 \mathrm{~cm}^{-1}$ ) rather than using model skin temperature. The campaign has demonstrated the potential of IASI observations to contribute to the monitoring of weather and climate over polar areas.

SUMMARY AND A LOOK TO THE FUTURE. In $5 \mathrm{yr}$ of operational service IASI has provided valuable new data, allowing important new developments in the fields of NWP and atmospheric composition analysis. The excellent calibration and stability of the instrument, and the expected long time series of data, indicate that it will also make important contributions to climate studies. New applications for IASI are still emerging as the data are investigated more thoroughly.

IASI has given significant positive forecast impact at NWP centers in both global and regional models, with data at a higher vertical resolution than has been seen before from an operational sounder. Unlike older operational sounders, significant amounts of IASI data can be used in cloudy conditions; nevertheless, more progress needs to be made to get closer to extracting the full information content in the observations.

IASI has also provided unprecedented atmospheric chemistry data, allowing near-real-time mapping of chemical species and aerosols, contributing to air traffic safety and to our understanding of atmospheric transport processes. Observations from IASI have unexpectedly allowed the detection from space of volatile chemical species, providing an ability to map sources and sinks of gases, such as ammonia.

It has already been shown that IASI exhibits sensitivity to the change in quantities of greenhouse gases, can be used to study cloud and aerosol properties, and will provide information on a range of other climate variables. It is expected that IASI will gather real-time information about the atmospheric state at higher vertical resolution, notably moisture and winds, and thus will form a critical component of the global observing system for climate studies.

Planning for the next generation of European satelliteborne interferometers is already underway. The Meteorological Satellite (Meteosat) Third Generation Infrared Sounder (MTG-IRS; www.eumetsat.int /Home/Main/Satellites/MeteosatThirdGeneration /index.htm?|=en) will be the first operational 
interferometer in geostationary orbit, providing high temporal resolution information on the atmospheric state for NWP and nowcasting. The frequent observations from geostationary orbit will also offer the opportunity of observing dynamics on shorter time scales than those from the polar orbit, and will allow real-time information on the Earth's wind fields to be generated. EUMETSAT's future polar-orbiting satellites will carry an interferometer of even higher spectral and radiometric resolution than IASI, extending the capabilities of the instrument to detect weakly absorbing trace gases and allowing the resolution of even more atmospheric features. These new instruments will build on the heritage of IASI, and on the science being demonstrated today with the MetOp satellite series.

ACKNOWLEDGMENTS. We would like to thank Bill Smith, John Eyre, and Lars Fiedler for their helpful comments while compiling this article. We also extend our appreciation to the anonymous reviewers for their constructive suggestions for improving the content of this paper.

\section{REFERENCES}

Aires, F., W. B. Rossow, N. A. Scott, and A. Chedin, 2002: Remote sensing from the infrared atmospheric sounding interferometer instrument 1. Compression, denoising, and first-guess retrieval algorithms. J. Geophys. Res., 107, 4619, doi:10.1029/2001JD000955.

Amato, U., V. Cuomo, R. Rizzi, and C. Serio, 1997: Evaluating the effect of the inter-relationships among the different spectral bands on IASI performances. Quart. J. Roy. Meteor. Soc., 123, 2231-2244, doi:10.1002/qj.49712354405.

- A. Antoniadis, I. De Feis, G. Masiello, M. Matricardi, and C. Serio, 2009: Technical note: Functional sliced inverse regression to infer temperature, water vapour and ozone from IASI data. Atmos. Chem. Phys., 9, 5321-5330, doi:10.5194/acp-9-5321-2009.

Atkinson, N. C., F. I. Hilton, S. M. Illingworth, J. R. Eyre, and T. Hultberg, 2010: Potential for the use of reconstructed IASI radiances in the detection of atmospheric trace gases. Atmos. Meas. Tech., 3, 991-1003, doi:10.5194/amt-3-991-2010.

Blumstein, D., B. Tournier, F. R. Cayla, T. Phulpin, R. Fjortoft, C. Buil, and G. Ponce, 2007: In-flight performance of the Infrared Atmospheric Sounding Interferometer (IASI) on METOP-A. Atmospheric and Environmental Remote Sensing Data Processing and Utilization III: Readiness for GEOSS,
M. D. Goldberg et al., Eds., International Society for Optical Engineering (SPIE Proceedings, Vol. 6684), 66840H, doi:10.1117/12.734162.

—, and Coauthors, 2010: AIRS/IASI intercomparison. Proc. Fifth GSICS Research Working Group, Toulouse, France, GSICS. [Available online at https://gsics.nesdis.noaa.gov/pub /Development/20100209/0830_Day3_AM_GRWG_ Blumstein_AIRS_IASI_inter-comparison.ppt.]

Bouchard, A., F. Rabier, V. Guidard, and F. Karbou, 2010: Enhancements of satellite data assimilation over Antarctica. Mon. Wea. Rev., 138, 2149-2173.

Boynard, A., and Coauthors, 2009: Measurements of total and tropospheric ozone from the IASI instrument: Comparison with satellite and ozonesonde observations. Atmos. Chem. Phys., 9, 6255-6271, doi:10.5194/acp-9-6255-2009.

Cao, C. Y., M. Goldberg, and L. Wang, 2009: Spectral bias estimation of historical HIRS using IASI observations for improved fundamental climate data records. J. Atmos. Oceanic Technol., 26, 1378-1387.

Capelle, V., A. Chédin, E. Péquignot, P. Schlüssel, S. M. Newman, and N. A. Scott, 2012: Infrared continental surface emissivity spectra and skin temperature retrieved from IASI observations over the tropics. J. Appl. Meteor. Climatol., in press.

Cardinali, C., 2009: Monitoring the observation impact on the short-range forecast. Quart. J. Roy. Meteor. Soc., 135, 239-250, doi:10.1002/qj.366.

Cayla, F.-R., 2001: L'interféromètre IASI, un nouveau sondeur satellitaire à haute résolution. Meteor., Ser. 8 (32), 23-39.

Chahine, M. T., and Coauthors, 2006: AIRS: Improving weather forecasting and providing new data on greenhouse gases. Bull. Amer. Meteor. Soc., 87, 911-926.

Chalon, G., F. Cayla, and D. Diebel, 2001: IASI: An advanced sounder for operational meteorology. Proc. 52nd Congress of IAF, Toulouse France, CNES. [Available online at http://smsc .cnes.fr/documentation/IASI/Publications /PRESENTATION_IAF_2001.pdf.]

Chédin, A., S. Serrar, N. A. Scott, C. Crevoisier, and R. Armante, 2003: First global measurement of mid-tropospheric $\mathrm{CO}_{2}$ from NOAA polar satellites: The tropical zone. J. Geophys. Res., 108, 4581, doi:10.1029/2003JD003439.

Clarisse, L., P. F. Coheur, A. J. Prata, D. Hurtmans, A. Razavi, T. Phulpin, J. Hadji-Lazaro, and C. Clerbaux, 2008: Tracking and quantifying volcanic $\mathrm{SO}_{2}$ with IASI, the September 2007 eruption at Jebel at Tair. Atmos. Chem. Phys., 8, 7723-7734, doi:10.5194/acp-8-7723-2008. 
- C. Clerbaux, F. Dentener, D. Hurtmans, and P.-F. Coheur, 2009: Global ammonia distribution derived from infrared satellite observations. Nat. Geosci., 2, 479-483, doi:10.1038/ngeo551.

— , and Coauthors, 2010a: Satellite monitoring of ammonia: A case study of the San Joaquin Valley. J. Geophys. Res., 115, D13302, doi:10.1029/2009JD013291.

- , D. Hurtmans, A. J. Prata, F. Karagulian, C. Clerbaux, M. De Mazière, and P.-F. Coheur, 2010b: Retrieving radius, concentration, optical depth, and mass of different types of aerosols from high-resolution infrared nadir spectra. Appl. Opt., 49, 3713-3722, doi:10.1364/AO.49.003713.

_, F. Prata, J.-L. Lacour, D. Hurtmans, C. Clerbaux, and P. Coheur, 2010c: A correlation method for volcanic ash detection using hyperspectral infrared measurements. Geophys. Res. Lett., 37, L19806, doi:10.1029/2010GL044828.

Clerbaux, C., and Coauthors, 2009: Monitoring of atmospheric composition using the thermal infrared IASI/ METOP sounder. Atmos. Chem. Phys., 9, 6041-6054, doi:10.5194/acp-9-6041-2009.

Coheur, P. F., L. Clarisse, S. Turquety, D. Hurtmans, and C. Clerbaux, 2009: IASI measurements of reactive trace species in biomass burning plumes. Atmos. Chem. Phys., 9, 5655-5667, doi:10.5194/acp-9-5655-2009.

Collard, A. D., 1998: Notes on IASI performance. Met Office Forecasting Research Tech. Rep. 256, 22 pp. [Available online at http://research.metoffice.gov .uk/research/nwp/publications/papers/technical_ reports/1998/FRTR256/FRTR256.pdf.]

,- 2007 : Selection of IASI channels for use in numerical weather prediction. Quart. J. Roy. Meteor. Soc., 133, 1977-1991, doi:10.1002/qj.178.

— , and A. P. McNally, 2009: The assimilation of Infrared Atmospheric Sounding Interferometer radiances at ECMWF. Quart. J. Roy. Meteor. Soc., 135, 1044-1058, doi:10.1002/qj.410.

,,-- F. I. Hilton, S. B. Healy, and N. C. Atkinson, 2010: The use of principal component analysis for the assimilation of High-Resolution Infrared Sounder observations for numerical weather prediction. Quart. J. Roy. Meteor. Soc., 136, 2038-2050, doi:10.1002/qj.701.

Crevoisier, C., S. Heilliette, A. Chédin, S. Serrar, R. Armante, and N. A. Scott, 2004: Midtropospheric $\mathrm{CO}_{2}$ concentration retrieval from airs observations in the tropics. Geophys. Res. Lett., 31, L17106, doi:10.1029/2004GL020141.

- , A. Chédin, H. Matsueda, T. Machida, R. Armante, and N. A. Scott, 2009a: First year of upper tropospheric integrated content of $\mathrm{CO}_{2}$ from IASI hyperspectral infrared observations. Atmos. Chem. Phys., 9, 4797-4810, doi:10.5194/acp-9-4797-2009.

—, D. Nobileau, A. Fiore, R. Armante, A. Chédin, and N. A. Scott, 2009b: Tropospheric methane in the tropics-First year from IASI hyperspectral infrared observations. Atmos. Chem. Phys., 9, 6337-6350, doi:10.5194/acp-9-6337-2009.

Dufour, G., M. Eremenko, J. Orphal, and J.-M. Flaud, 2010: IASI observations of seasonal and day-to-day variations of tropospheric ozone over three highly populated areas of China: Beijing, Shanghai, and Hong Kong. Atmos. Chem. Phys., 10, 3787-3801. doi:10.5194/acp-10-3787-2010.

Eremenko, M., G. Dufour, G. Foret, C. Keim, J. Orphal, M. Beekmann, G. Bergametti, and J.-M. Flaud, 2008: Tropospheric ozone distributions over Europe during the heat wave in July 2007 observed from infrared nadir spectra recorded by IASI. Geophys. Res. Lett., 35, L18805, doi:10.1029/2008GL034803.

Eyre, J., and F. Hilton, 2010: Beyond optimal estimation: Sensitivity of analysis error to the specification of background error. Tech. Proc. 17th Int. TOVS Study Conf., Monterey, CA, International TOVS Working Group. [Available online at http://cimss.ssec.wisc .edu/itwg/itsc/itsc17/papers.html.]

Foret, G., and Coauthors, 2009: Evaluating the potential of IASI ozone observations to constrain simulated surface ozone concentrations. Atmos. Chem. Phys., 9, 8479-8491, doi:10.5194/acp-9-8479-2009.

Fortems-Cheiney, A., and Coauthors, 2009: On the capability of IASI measurements to inform about CO surface emissions. Atmos. Chem. Phys., 9, 8735-8743, doi:10.5194/acp-9-8735-2009.

Gangale, G., A. J. Prata, and L. Clarisse, 2010: On the infrared spectral signature of volcanic ash. Remote Sens. Environ., 114, 414-425, doi:10.1016/j. rse.2009.09.007.

George, M., and Coauthors, 2009: Carbon monoxide distributions from the IASI/METOP mission: Evaluation with other space-borne remote sensors. Atmos. Chem. Phys., 9, 8317-8330, doi:10.5194/acp9-8317-2009.

Goldberg, M., Y. N. Qu, L. M. McMillin, W. Wolf, L. H. Zhou, and M. Divakarla, 2003: AIRS nearreal-time products and algorithms in support of operational numerical weather prediction. IEEE Trans. Geosci. Remote Sens., 41, 379-389, doi:10.1109/ TGRS.2002.808307.

— , and Coauthors, 2011: The Global Space-Based Inter-Calibration System. Bull. Amer. Meteor. Soc., 92, 467-475.

Grieco, G., G. Masiello, and C. Serio, 2010: Interferometric vs spectral IASI radiances: Effective data- 
reduction approaches for the satellite sounding of atmospheric thermodynamical parameters. Remote Sens., 2, 2323-2346, doi:10.3390/rs2102323.

,,,--- R. L. Jones, and M. I. Mead, 2011: Infrared atmospheric sounding interferometer correlation interferometry for the retrieval of atmospheric gases: The case of $\mathrm{H}_{2} \mathrm{O}$ and $\mathrm{CO}_{2}$. Appl. Opt., 50, 4516-4528, doi:10.1364/AO.50.004516.

Guidard, V., N. Fourrié, P. Brousseau, and F. Rabier, 2011: Impact of IASI assimilation at global and convective scales and challenges for the assimilation of cloudy scenes. Quart. J. Roy. Meteor. Soc., 137, 1975-1987, doi:10.1002/qj.928.

Han, W., and A. McNally, 2010: The 4D-Var assimilation of ozone-sensitive infrared radiances measured by IASI. Quart. J. Roy. Meteor. Soc., 136, 2025-2037, doi:10.1002/qj.708.

Herbin, H., D. Hurtmans, C. Clerbaux, L. Clarisse, and P.-F. Coheur, 2009: $\mathrm{H}_{2}{ }^{16} \mathrm{O}$ and HDO measurements with IASI/MetOp. Atmos. Chem. Phys., 9, 9433-9447, doi:10.5194/acp-9-9433-2009.

Hewison, T. J., 2008a: MetOp-A IASI and HIRS intercomparisons at Eumetsat. GSICS Quarterly, Vol. 2, No. 3, NOAA/NESDIS/STAR, 4-5. [Available online at www.star.nesdis.noaa.gov/smcd/GCC/documents /newsletter/GSICS_Quarterly_Vol2No3_2008.pdf.]

— , 2008b: SEVIRI/IASI differences in 2007. GSICS

Quarterly, Vol. 2, No. 1, NOAA/NESDIS/STAR, 1-2. [Available online at www.star.nesdis.noaa.gov/smcd /GCC/documents/newsletter/GSICS_Quarterly_ Vol2No1_2008.pdf.]

— , and M. König, 2008: Inter-Calibration of Meteosat imagers and IASI. Proc. of the 2008 EUMETSAT Meteorological Satellite Conf., Darmstadt, Germany, EUMETSAT. [Available online at www.eumetsat.int /idcplg?IdcService $=$ GET_FILE $\&$ dDocName $=$ PDF_ CONF_P_S2_02_HEWISON_V\&RevisionSelectio nMethod=LatestReleased.]

Hilton, F., and J. Eyre, 2010: The sensitivity of the suboptimal NWP analysis system to the representation of hyperspectral data. Tech. Proc. 17th Int. TOVS Study Conf., Monterey, CA, International TOVS Working Group. [Available online at http://cimss.ssec.wisc .edu/itwg/itsc/itsc17/papers/hilton_fiona-740.pdf.]

—, N. C. Atkinson, S. J. English, and J. R. Eyre, 2009a: Assimilation of IASI at the Met Office and assessment of its impact through observing system experiments. Quart. J. Roy. Meteor. Soc., 135, 495-505, doi:10.1002/qj.379.

—, A. Collard, V. Guidard, R. Randriamampianina, and M. Schwaerz, 2009b: Assimilation of IASI radiances at European NWR centres. ECMWF/ Eumetsat NWP-SAF Workshop on Assimilation of
IASI in NWP, Reading, United Kingdom, ECMWF. [Available online at www.ecmwf.int/publications /library/ecpublications/_pdf/workshop/2009/IASI /Hilton.pdf.]

Illingworth, S. M., J. J. Remedios, and R. J. Parker, 2009: Intercomparison of integrated IASI and AATSR calibrated radiances at 11 and $12 \mu \mathrm{m}$. Atmos. Chem. Phys., 9, 6677-6683, doi:10.5194/acp-9-6677-2009.

—, - - H. Boesch, S.-P. Ho, D. P. Edwards, P. I. Palmer, and S. Gonzi, 2011a: A comparison of OEM $\mathrm{CO}$ retrievals from the IASI and MOPITT instruments. Atmos. Meas. Tech., 4, 775-793, doi:10.5194/ amt-4-775-2011.

,,--- , D. P. Moore, H. Sembhi, A. Dudhia, and J. C. Walker, 2011b: ULIRS, an optimal estimation retrieval scheme for carbon monoxide using IASI spectral radiances: Sensitivity analysis, error budget and simulations. Atmos. Meas. Tech., 4, 269-288, doi:10.5194/amt-4-269-2011.

Jacquinet-Husson, N., N. A. Scott, A. Chédin, and A. A. Chursin, 2003: The GEISA spectroscopic database system revisited for IASI direct radiative transfer modelling. Atmos. Oceanic Opt., 16, 256-82.

— GEISA/IASI spectroscopic database. J. Quant. Spectrosc. Radiat. Transfer, 95, 429-467, doi:10.1016/j. jqsrt.2004.12.004.

—, and Coauthors, 2008: The GEISA spectroscopic database: Current and future archive for earth and planetary atmosphere studies. J. Quant. Spectrosc. Radiat. Transfer, 109, 1043-1059, doi:10.1016/j. jqsrt.2007.12.015.

— , and Coauthors, 2011: The 2009 edition of the GEISA spectroscopic database. J. Quant. Spectrosc. Radiat. Transfer, 112, 2395-2445, doi:10.1016/j. jqsrt.2011.06.004.

Karagulian, F., L. Clarisse, C. Clerbaux, A. J. Prata, D. Hurtmans, and P.-F. Coheur, 2010: Detection of volcanic $\mathrm{SO}_{2}$, ash, and $\mathrm{H}_{2} \mathrm{SO}_{4}$ using the Infrared Atmospheric Sounding Interferometer (IASI). J. Geophys. Res., 115, D00L02, doi:10.1029/2009JD012786.

Keim, C., and Coauthors, 2009: Tropospheric ozone from IASI: Comparison of different inversion algorithms and validation with ozone sondes in the northern middle latitudes. Atmos. Chem. Phys., 9, 9329-9347, doi:10.5194/acp-9-9329-2009.

Klaes, K. D., and Coauthors, 2007: An introduction to the EUMETSAT polar system. Bull. Amer. Meteor. Soc., 88, 1085-1096.

Larar, A. M., W. L. Smith, D. K. Zhou, X. Liu, H. Revercomb, J. P. Taylor, S. M. Newman, and P. Schlüssel, 2010: IASI spectral radiance validation inter-comparisons: Case study assessment from the 
JAIVEx field campaign. Atmos. Chem. Phys., 10, 411-430, doi:10.5194/acp-10-411-2010.

Lavanant, L., and Coauthors, 2010: Comparison of cloud products within IASI footprints for the assimilation of cloudy radiances. Quart. J. Roy. Meteor. Soc., 137, 1988-2003, doi:10.1002/qj.917.

Li, J., C. Y. Liu, H. L. Huang, T. J. Schmit, X. B. Wu, W. P. Menzel, and J. J. Gurka, 2005: Optimal cloud-clearing for AIRS radiances using MODIS. IEEE Trans. Geosci. Remote Sens., 43, 1266-1278, doi:10.1109/TGRS.2005.847795.

Liu, X., W. L. Smith, D. K. Zhou, and A. Larar, 2006: Principal component-based radiative transfer model for hyperspectral sensors: Theoretical concept. Appl. Opt., 45, 201-209, doi:10.1364/AO.45.000201.

—, D. K. Zhou, A. M. Larar, W. L. Smith, P. Schlüssel, S. M. Newman, J. P. Taylor, and W. Wu, 2009: Retrieval of atmospheric profiles and cloud properties from IASI spectra using super-channels. Atmos. Chem. Phys., 9, 9121-9142, doi:10.5194/acp-9-91212009.

Maring, H., D. L. Savoie, M. A. Izaguirre, L. Custals, and J.S. Reid, 2003: Mineral dust aerosol size distribution change during atmospheric transport. J. Geophys. Res., 108, 8592, doi:10.1029/2002JD002536.

Masiello, G., and C. Serio, 2004: Dimensionalityreduction approach to the thermal radiative transfer equation inverse problem. Geophys. Res. Lett., 31, L11105, doi:10.1029/2004GL019845.

,-- , A. Carissimo, G. Grieco, and M. Matricardi, 2009: Application of $\bigotimes$-IASI to IASI: Retrieval products evaluation and radiative transfer consistency. Atmos. Chem. Phys., 9, 8771-8783, doi:10.5194/acp9-8771-2009.

,$- \ldots$, P. Antonelli, 2011: Inversion for atmospheric thermodynamical parameters of IASI data in the principal components space. Quart. J. Roy. Meteor. Soc., 138, 103-117, doi:10.1002/qj.909.

McNally, A. P., 2009: The direct assimilation of cloudaffected satellite infrared radiances in the ECMWF 4D-Var. Quart. J. Roy. Meteor. Soc., 135, 1214-1229, doi:10.1002/qj.426.

— , and P. D. Watts, 2003: A cloud detection algorithm for high-spectral-resolution infrared sounders. Quart. J. Roy. Meteor. Soc., 129, 3411-3423. doi:10.1256/qj.02.208.

Newman, S. M., F. Hilton, J. P. Taylor, A. D. Collard, W. L. Smith, and A. Larar, 2008: Direct radiance validation of IASI-Results from JAIVEx. Tech. Proc. 16th Int. TOVS Study Conf., Angra Dos Reis, Brazil, International TOVS Working Group. [Available online at http://cimss.ssec.wisc.edu/itwg/itsc/itsc16 /presentations/02_08_newman.pdf.]
Pangaud, T., N. Fourrié, V. Guidard, M. Dahoui, and F. Rabier, 2009: Assimilation of AIRS radiances affected by mid- to low-level clouds. Mon. Wea. Rev., 137, 4276-4292.

Pavelin, E. G., S. J. English, and J. R. Eyre, 2008: The assimilation of cloud-affected infrared satellite radiances for numerical weather prediction. Quart. J. Roy. Meteor. Soc., 134, 737-749, doi:10.1002/qj.243.

Péquignot, E., A. Chédin, and N. A. Scott, 2008: Infrared continental surface emissivity spectra retrieved from AIRS hyperspectral sensor. J. Appl. Meteor. Climatol., 47, 1619-1633.

Peyridieu, S., 2010: Etablissement d'une climatologie des propriétés des aérosols de poussières à partir d'observations hyperspectrales dans l'infrarouge: Application aux instruments AIRS et IASI. Ph.D. thesis, Université Pierre et Marie Curie, 240 pp. [Available online at http://ara .abct.lmd.polytechnique.fr/thesis/2010_These_ SophiePeyridieu_final_protected.pdf.]

- - A. Chédin, D. Tanré, V. Capelle, C. Pierangelo, N. Lamquin, and R. Armante, 2010: Saharan dust infrared optical depth and altitude retrieved from AIRS: A focus over north Atlantic-Comparison to MODIS and CALIPSO. Atmos. Chem. Phys., 10, 1953-1967, doi:10.5194/acp-10-1953-2010.

Pierangelo, C., A. Chédin, S. Heilliette, N. JacquinetHusson, and R. Armante, 2004: Dust altitude and infrared optical depth from AIRS. Atmos. Chem. Phys., 4, 1813-1822, doi:10.5194/acp-4-1813-2004.

_- M. Mishchenko, Y. Balkanski, and A. Chédin, 2005: Retrieving the effective radius of Saharan dust coarse mode from AIRS. Geophys. Res. Lett., 32, L20813, doi:10.1029/2005GL023425.

Pommier, M., and Coauthors, 2010: IASI carbon monoxide validation over the arctic during POLARCAT spring and summer campaigns. Atmos. Chem. Phys., 10, 10655-10 78, doi:10.5194/acp-10-10655-2010.

Pougatchev, N., and Coauthors, 2009: IASI temperature and water vapor retrievals-Error assessment and validation. Atmos. Chem. Phys., 9, 6453-6458, doi:10.5194/acp-9-6453-2009.

Prunet, P., J.-N. Thépaut, and V. Cassé, 1998: The information content of clear sky IASI radiances and their potential for numerical weather prediction. Quart. J. Roy. Meteor. Soc., 124, 211-241, doi:10.1002/ qj.49712454510.

—, S. Bijac, and J. Donadille, 2007: Traitement des scenes hétérogènes. IASI Rep. Nov-3396-Nt-4971, CNES.

Rabier, F., and Coauthors, 2010: The concordiasi project in Antarctica for the International Polar Year (IPY). Bull. Amer. Meteor. Soc., 91, 69-86. 
Rädel, G., C. J. Stubenrauch, R. Holz, and D. L. Mitchell, 2003: Retrieval of effective ice crystal size in the infrared: Sensitivity study and global measurements from the TIROS-N operational vertical sounder. J. Geophys. Res., 108, 4281, doi:10.1029/2002JD002801.

Razavi, A., F. Karagulian, L. Clarisse, D. Hurtmans, P.-F. Coheur, C. Clerbaux, J. F. Müller, and T. Stavrakou, 2011: Global distributions of methanol and formic acid retrieved for the first time from the IASI/METOP thermal infrared sounder. Atmos. Chem. Phys., 11, 857-872, doi:10.5194/acp-11-8572011.

Ricaud, P., J.-L. Attié, H. Teyssèdre, L. El Amraoui, V.-H. Peuch, M. Matricardi, and P. Schluessel, 2009: Equatorial total column of nitrous oxide as measured by IASI on MetOp-A: Implications for transport processes. Atmos. Chem. Phys., 9, 3947-3956, doi:10.5194/acp-9-3947-2009.

Rix, M., and Coauthors, 2009: Satellite monitoring of volcanic sulfur dioxide emissions for early warning of volcanic hazards. IEEE Trans. Geosci. Remote Sens., 3, 196-206, doi:10.1109/JSTARS.2009.2031120.

Rossow, W. B., and R. A. Schiffer, 1999: Advances in understanding clouds from ISCCCP. Bull. Amer. Meteor. Soc., 80, 2261-2287.

Rothman, L. S., and Coauthors, 2009: The HITRAN 2008 molecular spectroscopic database. J. Quant. Spectrosc. Radiat. Transfer, 110, 533-572, doi:10.1016/j. jqsrt.2009.02.013.

Schlüssel, P., T. H. Hultberg, P. L. Phillips, T. August, and X. Calbet, 2005: The operational IASI level 2 processor. Adv. Space Res., 36, 982-988, doi:10.1016/j. asr.2005.03.008.

Scott, N. A., and Coauthors, 1999: Characteristics of the TOVS pathfinder path-B dataset. Bull. Amer. Meteor. Soc., 80, 2679-2701.

Siméoni, D., and Coauthors, 2004: Design and development of IASI instrument. Infrared Spaceborne Remote Sensing XII, M. Strojnik, Ed., International Society for Optical Engineering (SPIE Proceedings, Vol. 5543), 208-219, doi:10.1117/12.561090.

Smith, W. L., Sr., and Coauthors, 2009: Evolution, current capabilities, and future advances in satellite ultra-spectral IR sounding. Atmos. Chem. Phys., 9, 5563-5574, doi:10.5194/acp-9-5563-2009.

Sodemann, H., and Coauthors, 2011: Episodes of crosspolar transport in the arctic troposphere during July 2008 as seen from models, satellite, and aircraft observations. Atmos. Chem. Phys., 11, 3631-3651, doi:10.5194/acp-11-3631-2011.

Stengel, M., M. Lindskog, P. Undén, N. Gustaffson, and R. Bennartz, 2010: An extended observation operator in HIRLAM 4D-VAR for the assimilation of cloudaffected satellite radiances. Quart. J. Roy. Meteor. Soc., 136, 1064-1074, doi:10.1002/qj.621.

Strow, L. L., and S. E. Hannon, 2008: A 4-year zonal climatology of lower tropospheric $\mathrm{CO}_{2}$ derived from ocean-only Atmospheric Infrared Sounder observations. J. Geophys. Res., 113, D18302, doi:10.1029/2007JD009713.

Stubenrauch, C. J., W. B. Rossow, F. Chéruy, A. Chédin, and N. A. Scott, 1999: Clouds as seen by satellite sounders (3I) and imagers (ISCCP). Part I: Evaluation of cloud parameters. J. Climate, 12, 2189-2213.

—, A. Chédin, G. Rädel, N. A. Scott, and S. Serrar, 2006: Cloud properties and their seasonal and diurnal variability from TOVS path-B. J. Climate, 19, 5531-5553.

-, S. Cros, A. Guignard, and N. Lamquin, 2010: A 6-year global cloud climatology from the Atmospheric InfraRed Sounder AIRS and a statistical analysis in synergy with CALIPSO and CloudSat. Atmos. Chem. Phys., 10, 7197-7214, doi:10.5194/ acp-10-7197-2010.

Té, Y., P. Jeseck, C. Camy-Peyret, S. Payan, G. Perron, and G. Aubertin, 2002: Balloonborne calibrated spectroradiometer for atmospheric nadir sounding. Appl. Opt., 41, 6431-6441, doi:10.1364/AO.41.006431.

Thelen, J. C., S. Havemann, S. M. Newman, and J. P. Taylor, 2010: Hyperspectral retrieval of land surface emissivities using AIRES. Quart. J. Roy. Meteor. Soc., 135, 2110-2124, doi:10.1002/qj.520.

Tobin, D., 2008: An SNO analysis of IASI and AIRS spectral radiance. GSICS Quarterly, Vol. 2, No. 3, NOAA/NESDIS, 2-4. [Available at www.star .nesdis.noaa.gov/smcd/GCC/documents/newsletter /GSICS_Quarterly_Vol2No3_2008.pdf.]

Turquety, S., D. Hurtmans, J. Hadji-Lazaro, P.-F. Coheur, C. Clerbaux, D. Josset, and C. Tsamalis, 2009: Tracking the emission and transport of pollution from wildfires using the IASI CO retrievals: Analysis of the summer 2007 Greek fires. Atmos. Chem. Phys., 9, 4897-4913, doi:10.5194/acp-9-4897-2009.

UNEP, 2009: Handbook for the Montreal Protocol on substances that deplete the ozone layer. 8th ed. United Nations Environmental Program, 588 pp. [Available online at http://ozone.unep.org/Publications/MP Handbook/MP-Handbook-2009.pdf.]

Walker, J. C., A. Dudhia, and E. Carboni, 2011: An effective method for the detection of trace species demonstrated using the MetOp Infrared Atmospheric Sounding Interferometer. Atmos. Meas. Tech., 4, 1567-1580, doi:10.5194/amt-4-1567-2011.

Wang, L., and C. Cao, 2008: On-orbit calibration assessment of AVHRR longwave channels on MetOp-A 
using IASI. IEEE Trans. Geosci. Remote Sens., 46, 4005-4013, doi:10.1109/TGRS.2008.2001062.

Wespes, C., D. Hurtmans, C. Clerbaux, M. L. Santee, R. V. Martin, and P.-F. Coheur, 2009: Global distributions of nitric acid from IASI/MetOp measurements. Atmos. Chem. Phys., 9, 7949-7962, doi:10.5194/acp9-7949-2009.

Winker, D. M., M. A. Vaughan, A. Omar, Y. Hu, and K. A. Powell, 2009: Overview of the CALIPSO mission and CALIOP data processing algorithms. J. Atmos. Oceanic Technol., 26, 2310-2323.
Zhou, D. K., W. L. Smith, A. M. Larar, X. Liu, J. P. Taylor, P. Schlüssel, L. L. Strow, and S. A. Mango, 2009: All weather IASI single field-of-view retrievals: Case study-Validation with JAIVEx data. Atmos. Chem. Phys., 9, 2241-2255, doi:10.5194 lacp-9-2241-2009.

—, A. M. Larar, X. Liu, W. L. Smith, L. L. Strow, P. Yang, P. Schlüssel, and X. Calbet, 2011: Global land surface emissivity retrieved from satellite ultraspectral IR measurements. IEEE Trans. Geosci. Remote Sens., 49, 1277-1290, doi:10.1109/TGRS.2010.2051036.

\section{NEW FROM AMS BOOKS!}

"This book is timely because global climate change policy is a mess.... Drawing on concrete examples and a broad range of social science theory, this book convincingly makes the case for a social learning approach to both adaptation and emissions mitigation."

- Steve Rayner, James Martin Professor of Science and Civilization, University of Oxford

\section{Adaptive Governance and Climate Change}

RONALD D. BRUNNER AND AMANDA H. LYNCH

As greenhouse gas emissions and temperatures at the poles continue to rise, so do damages from extreme weather events affecting countless lives. Meanwhile, ambitious international efforts to cut emissions have proved to be politically ineffective or infeasible. There is hope, however, in adaptive governance-an approach that has succeeded in some communities and can be undertaken by others around the globe. In this book:

- A political and historical analysis of climate change policy

- How adaptive governance works on the ground

- Why local, bottom-up approaches should complement global-scale negotiations

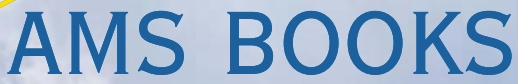

RESEARCH APPLICATIONS HISTORY www.ametsoc.org/amshookstore • 617-227-2426 ext 686 